\title{
BIM for Healthy Buildings: An Integrated Approach of Architectural Design Based on IAQ Prediction
}

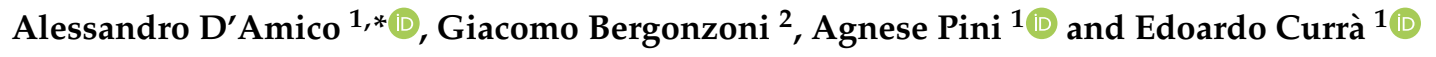 \\ 1 Department of Civil, Building and Environmental Engineering, Sapienza University of Rome, 00184 Rome, \\ Italy; agnese.pini@uniroma1.it (A.P.); edoardo.curra@uniroma1.it (E.C.) \\ 2 Department of Architecture, Alma Mater Studiorum University of Bologna, 40141 Bologna, Italy; \\ giacomo.bergonzoni3@unibo.it \\ * Correspondence: alessandro.damico@uniroma1.it; Tel.: +39-064-458-5665
}

Received: 20 November 2020; Accepted: 9 December 2020; Published: 12 December 2020

\begin{abstract}
The relationship between users and the built environment represents a fundamental aspect of health. The factors that define the properties linked to health and well-being are increasingly becoming part of building design. In these terms, building information modelling (BIM) and BIM-based performance simulation take on a priority role. Among the key features for the design of Healthy Buildings, indoor air quality (IAQ) plays a central role. There are numerous indoor pollutants with significant health effects; volatile organic compounds (VOCs) are to be mentioned among these. The paper presents the proposal of an integrated workflow in the BIM process for the check and control of VOC emissions from building materials and their concentration in confined environments. The workflow is developed through the systematisation of IAQ parameters for the open BIM standard, the integration in the BIM process of a numerical model for the prediction of the VOCs concentration in the indoor environment, and the development of model checkers for performance verification. The results show a good adhesion between the numerical model and the implementation in BIM, providing the designer with a rapid control instrument of IAQ in the various phases of the building design. The present study is the first development focused on TVOC, but implementable concerning other aspects of IAQ, as needed for the effectiveness of performance building-based design for health and wellness issues.
\end{abstract}

Keywords: design and health; BIM; materials; interior design; salutogenesis; wellbeing; VOC emission; IAQ; building design

\section{Introduction}

Architectural design in health management is assuming an increasingly central role. In this context, the issue of building quality requires the development of models for verifying the feasibility of the building project and the optimal compliance of the works with the requirements. This objective needs an interdisciplinary approach as the technological and construction solutions must be based on the maximum interrelation between the building organism, the environmental system, and the building-plant system [1].

Considering the humankind-built environment relationship, determined in every situation delimited by the confined environment, the main requirements to be met refer to a series of technological, environmental, and functional aspects directly and indirectly connected to the quality intended to confer on the built environment. The management of these interrelations requires the adoption of building information models that govern the complexity of the building organism [2,3] by simulating its real behaviour in the aspects of a constructive, functional, and formal nature, and the system hierarchies. For this reason, research on the translation of the building system in terms of assisted design assumes 
a priority role. The coding of BIM grows on the trend of research regarding the decomposition of the building system [4] into technological-functional elements and their consequent organisation in hierarchies of systems, defined and structured according to their mutual relationships [5].

The World Health Organization (WHO) has recognised the influence of the indoor and outdoor built environment on public health, with particular attention to densely built-up contexts [6]. Adequate living conditions require a healthy built environment, as much as individual and collective health is affected by the environmental context [7].

As highlighted by the EPA [8], the reduction of health risks must be achieved through better design, construction, and management of buildings, improvements in the development and use of interior material, and mitigation of existing exposures inside a building or in its immediate vicinity. Numerous current researches deal with the quality of indoor environments and their impact on health [8-11], to achieve the definition of the "Healthy Buildings" concept [12]. Through a complete set of scientific evidence drawn from a substantial review of the scientific literature, the study conducted by the Harvard School of Public Health [12] identifies the nine fundamental elements for "Healthy Buildings": Ventilation; indoor air quality (IAQ); thermal health; humidity; dust and parasites; security and protection; water quality; noise pollution; lighting and view.

In recent decades, numerous studies have focused on IAQ $[13,14]$, documenting profound qualitative changes in indoor air, with a progressive increase in the absolute number of pollutants [15], many of which have significant effects on health [8]. The pollutants detectable in indoor environments are numerous and range from biological ones (mites, fungal spores) to chemical ones (i.e., $\mathrm{NO} 2, \mathrm{CO}$, polycyclic aromatic hydrocarbons-PAH, benzene, volatile organic compounds-VOC, formaldehyde, PM10, PM2.5), often showing higher concentrations than those detectable outsides [16]. In particular, VOCs are widely diffused in indoor environments as they can be emitted by construction and finishing materials, furniture and equipment, and cleaning products.

In Italy, as in the rest of the world, following the energy resources crisis, new technical-design criteria have been imposed for buildings for civil use. The need to contain consumption for heating and ventilation has imposed better thermal insulation of buildings, with a consequent trend to seal the indoor environments, and to replace the natural methods of ventilation and lighting with artificial means [17]. This approach has made the architectural design more involved in indoor air quality.

We are entering the Third Era of Health, where the figures involved in the construction process have a real opportunity to provide salutogenic as well as healthy environments, not only concerning hospital construction but also to the whole built environment. The goal is to create optimal living environments that seriously support well-being and health in both private and public settings [18]. While the First Era focused on communicable diseases, and the Second Era, which began in the mid-20th century, converged attention on chronic diseases, the current one is centred on the concepts of "healthy" and "salutogenesis", i.e., quantitative issues of health "as the ability to maintain and improve health as a resource for living" [19].

The concept of salutogenic design originates from Aaron Antonovsky's theory of "salutogenesis", developed in 1979. The term translates to "origins of health", focusing on actively promoting the concept of health and well-being, rather than the pathogenic approach that deals exclusively with resulting diseases and injuries. Several studies, integrated between scientific research and design practice, are taking an interest in the topic. Among these is the work of the TH!NK group, research and development team dedicated to healthcare design within the IBI Group, and responsible for the "Salutogenic Home of Tomorrow" project [18].

The theme of salutogenic design has also pervaded the design of workplaces, which, like all indoor environments, can contain numerous factors dangerous to health [13], and this is also related to the cost reduction paradigm, in which space efficiency takes priority over users requirements [20]. The mitigation of pathogenic environmental components is a necessary, but not sufficient step towards the goal of providing genuinely healthy workplaces. According to Roskams and Haynes [20], two main strategies for improvement in workplaces are possible: Making physical alterations to 
the site aimed at reducing the presence of requests (for example increasing the ventilation rate to improve air quality) and increasing the presence of resources (for example bringing plants into the indoor environment). The recent certification schemes for the optimisation of health and well-being in the built environment (i.e., the WELL Building standard [21]) focus largely on improving indoor environmental quality through strategies such as minimising air pollutants and reducing various sources of environmental distress.

The distinction between harmful and health-promoting factors echoes the World Health Organization's definition of health (1948) as "state of complete physical, mental and social well-being and not merely the absence of disease or infirmity" [11].

Thus, architectural design in health management is playing a new role and, as written at the beginning, the system of requirements to be met refers to the aspects of the technological and the environmental systems directly or indirectly connected to the quality of the indoor built environment.

The management of these interrelations through building information models [2,3] follows a requirement-performance approach aimed to define the technical intervention methods on building construction to respond to the demands of the functional programming, and of the current legislation with compliant technical solutions, characterised more or less by high performance [22,23], and specifically for health and well-being requirements.

Not coincidentally, scientific literature in the field had already highlighted the importance of these needs by grouping them into a specific class [UNI 11277:2006 withdrawn March 2017-and partly assimilated by the enactment of the Minimum Environmental Criteria-Criteri Ambientali Minimi CAM-Italian Ministerial Decree 11 October 2017], given that the population spends on average over $90 \%$ of their time inside built spaces [8,17]. From this point of view, it is in the complete development of the concept of performance-based building design (PBBD) [24] that it is possible to think of significant results.

From an operational point of view, the issue to be overcome as a difficulty is to associate a performance specification (threshold value) to each element of the environmental and technological system [25] by filling in data fields or using automated calculation procedures [26]. One of the main problems appears to be the incomplete definition of the performance specifications in the regulatory environment concerning specific topics.

With specific reference to IAQ, the need to regulate exposure levels has led international organisations, such as the WHO, to define guide values (indoor air guide values-IAGVs) [27] for the concentration of various pollutants in an indoor environment, and which scientific knowledge regarding the effects on humans has been judged sufficiently reliable. The substances considered are benzene, nitrogen dioxide, polycyclic aromatic hydrocarbons (especially benzo[a]pyrene), naphthalene, carbon monoxide, radon, trichloroethylene, and tetrachlorethylene. Many countries have then developed their own standards defining the limits of numerous VOCs. In most countries, in line with the WHO, the guide values refer to individual substances. Only in a limited number of countries (e.g., Portugal, the Netherlands, Belgium) has an acceptability limit been defined for total VOCs [11,28]. In Italy, a specific standard that incorporates WHO guidelines has not been drawn up [8], while Ministerial Decree of 11 October 2017 dictates the minimum environmental criteria (CAM) for construction and exclusively defines the limits of emissions from materials, but not those to concentrations in the indoor environment.

To overcome the incomplete definition of performance specifications in the regulatory field, it is necessary to rely on an evidence-based approach, addressing the possibility of attributing, and above all extrapolating, quantitative assessments from the information models for design. [29].

As highlighted by Zanchetta [1], the objective of this approach is currently linked to the coordination of the different disciplinary contributions, which must lead to a coherent set of design choices and calculation approaches.

The field of research that deals with BIM and GreenBuildings, in the broadest sense of the term, is expanding to these aspects [30] and the use of model checking software is now widespread, to verify 
the correctness of the design. The interest in research and application of BIM now has a broad and shared development concerning the issues of the energy performance of the building, while there are shortcomings for issues relating to health and well-being, such as IAQ [31,32]. Starting from a digital classification of the building elements based on the development and adoption of the buildingSMART ${ }^{\circledR}$ standards, namely the IFC (Industry Foundation Classes) standard for openBIM, it is possible to verify the relationships established between them to set rules, check, and verify the correctness of the design choices [33-35]. For example, Cofaigh et al. configured the shape and orientation of a low-energy building using BIM-based analysis, achieving a $40 \%$ reduction in the environmental and financial burden compared to a conventional building [36]. Wang et al. used a BIM-based energy analysis simulation tool to analyse different building materials and set parameters optimised for environmental impact assessment [37]. Getuli et al. developed a model checking for the safety aspects of the construction site [38]. In particular, there are numerous applications relating to the seventh dimension of BIM, the one of sustainability, such as the one carried out by Open Project on the integration between BIM and LEED certification, specifically of indoor environmental quality (IEQ) [39], and related to the life cycle assessment (LCA) [40].

The paper presents the proposal for an applicative workflow and a tool integrated into the BIM process for the check and control of VOC emissions from building materials and their concentration in confined environments, referred to national and international standards, and to guide values for IAQ (IAGVs). What presented here is part of broader research "BIM4H\&W: BIM for Health and Wellbeing" (POR FESR LAZIO 2014/2020- Integrated projects) developed in partnership of effective collaboration between the company RI.EL.CO IMPIANTI S.R.L. and the University of Rome "La Sapienza", CRITEVAT.

\section{Materials and Methods}

The methodology developed in the research followed the workflow represented in Figure 1.

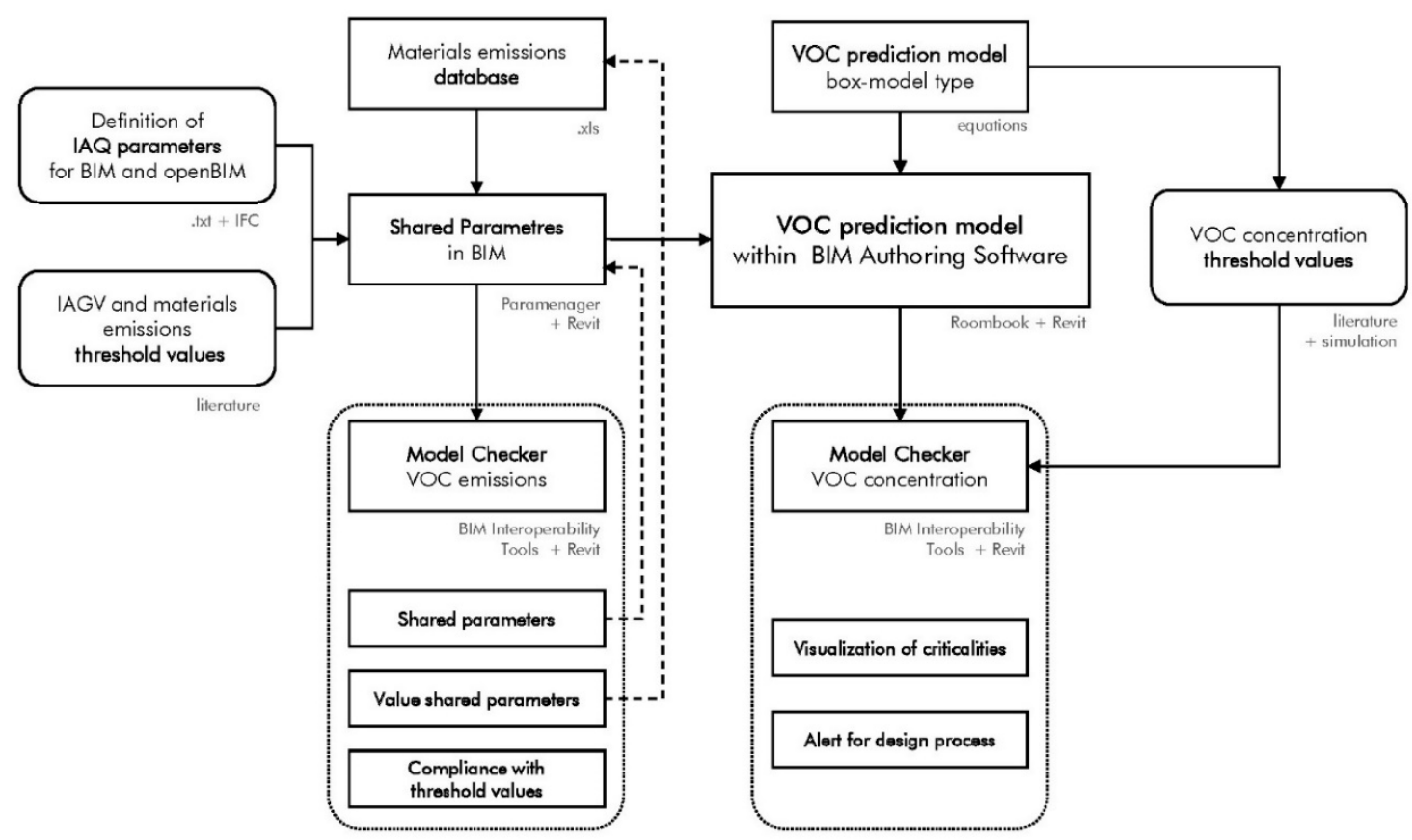

Figure 1. Integration of indoor air quality (IAQ) issues and volatile organic compound (VOC) prediction model within the building information modelling (BIM) process workflow.

The four main sections, in which the methodology is divided, are set out below: (i) Definition of IAQ parameters to be implemented in BIM process and IFC standard; (ii) development of an automatised process to apply parameters to BIM elements; (iii) use of BIM to integrate the VOC 
prediction model; (iv) development of model checker in the BIM process to verify indoor TVOC concentration related to IAGVs to address design choices. The research was developed on the case study: the new expansion of CNR in Pisa, Italy.

\subsection{IAQ Parameters to Be Implemented in the BIM Process and IFC Standard}

The IFC standard is continually evolving and provides for the change and addition of new standard property sets for objects from one version to another; for this reason, we want to propose a new property set useful for containing all the information concerning the indoor air quality (IAQ).

Methodologically, the research starts from the review of the parameters for the control of IAQ found in the property sets already provided in the IFC 4.1 schema [41].

Property sets already containing parameters that can be used for the model use of this research have been identified: Analysis of indoor air quality. Starting from the "common property sets", the following specific property sets were also analysed in-depth:

- IfcMaterial: Pset_MaterialThermal, Pset_MaterialCombustion.

- IfcWall, IfcSlab, IfcCeiling, IfcCovering: Pset_EnvironmentalImpactIndicators, Pset_Environ mentalImpactValues.

- IfcSpace: Pset_SpaceThermalRequirements, Pset_SpaceThermalDesign, Pset_SpaceCovering Requirements, Qto_SpaceBaseQuantities.

The survey shows that only some parameters, referring to the IfcSpace entity belonging to the Pset_SpaceThermalRequirements and Qto_SpaceBaseQuantities, can be used for the workflow aimed at managing VOC emissions (Table 1).

Table 1. Parameters for managing VOC emissions already provided for in the IFC 4.1 schema.

\begin{tabular}{|c|c|c|c|}
\hline $\begin{array}{l}\text { Parameter } \\
\text { Name }\end{array}$ & Parameter Description & $\begin{array}{l}\text { Assigned } \\
\text { Items }\end{array}$ & $\begin{array}{c}\text { PropertySet or } \\
\text { QuantitySet Reference }\end{array}$ \\
\hline NetWallArea & $\begin{array}{l}\text { Sum of all wall (and other vertically } \\
\text { bounding elements, like columns) areas } \\
\text { bounded by the space. It excludes the area } \\
\text { covered by elements inside the wall area } \\
\text { (doors, windows, other openings, etc.). }\end{array}$ & IfcSpace & $\begin{array}{c}\text { IFC } 4.1 \\
\text { Qto_SpaceBaseQuantities }\end{array}$ \\
\hline NetFloorArea & $\begin{array}{l}\text { Sum of all usable floor areas covered by the } \\
\text { space. It excludes the area covered by } \\
\text { elements inside the space (columns, inner } \\
\text { walls, built-in's etc.), slab openings, or other } \\
\text { protruding elements. Varying heights are not } \\
\text { taking into account (i.e. no reduction for } \\
\text { areas under a minimum headroom). }\end{array}$ & IfcSpace & $\begin{array}{c}\text { IFC 4.1 } \\
\text { Qto_SpaceBaseQuantities }\end{array}$ \\
\hline NetCeilingArea & $\begin{array}{l}\text { Sum of all ceiling areas of the space. It } \\
\text { excludes the area covered by elements inside } \\
\text { space (columns, inner walls, etc.). The ceiling } \\
\text { area is the real (and not the projected) area } \\
\text { (e.g. in case of sloped ceilings). }\end{array}$ & IfcSpace & $\begin{array}{c}\text { IFC } 4.1 \\
\text { Qto_SpaceBaseQuantities }\end{array}$ \\
\hline NetVolume & $\begin{array}{c}\text { Net volume enclosed by the space, excluding } \\
\text { the volume of construction elements inside } \\
\text { the space. }\end{array}$ & IfcSpace & $\begin{array}{c}\text { IFC } 4.1 \\
\text { Qto_SpaceBaseQuantities }\end{array}$ \\
\hline $\begin{array}{c}\text { Mechanical } \\
\text { VentilationRate }\end{array}$ & $\begin{array}{l}\text { Indication of the requirement of a particular } \\
\text { mechanical air ventilation rate, given in air } \\
\text { changes per hour. }\end{array}$ & IfcSpace & $\begin{array}{c}\text { IFC } 4.1 \\
\text { Pset_SpaceThermalRequirements }\end{array}$ \\
\hline
\end{tabular}

For this reason, it needs to identify and propose additional parameters in addition to those already provided for by the IFC 4.1 schema, necessary for the analysis of the IAQ.

The identification of these parameters is an instrumental result to achieve the broader objectives of the research. For this reason, it is necessary to have selection criteria proportionate to the final purpose. First of all, to make the use of new/implemented property sets in BIM by operators easy 
and widespread, it is good practice not to excessively multiply the number of them, for effective assimilation of the search results in the design/professional practice.

Therefore, to achieve these objectives, two fundamental criteria stay at the basis of the definition of the new parameters:

1. Enter as few parameters as possible, using a parameter with the same name for different IFC entities. For example, "VOCsEmission" is assigned to both the materials and objects of the model (i.e., walls, floors, false ceilings), obviously, in the first case the value will express the emissivity of the VOCs of the single material, while in the second case it will express the emissivity of all the materials that make up the object;

2. Use a composition of the name as consistent as possible with that of the international standard IFC 4.1, currently the official schema.

Thus it is possible to propose the two new property sets "Pset_IndoorAirQualityRequirements" and "Pset_SpaceIndoorAirQualityRequirements" and Tables 2 and 3 show, respectively, the proposed parameters that will compose them. This procedure aims to increase the LOD (level of development) of the information model, in detail of the non-geometric aspects, i.e., the LOI (level of information).

Table 2. "Pset_IndoorAirQualityRequirements" and the parameters that compose it.

\begin{tabular}{ccc}
\hline Parameter Name & Parameter Description & Entities to Which It Is Assigned \\
\hline VOCsEmission & Quantity of VOCs emissions for elements. & IfcMaterial, IfcWall, IfcSlab, \\
& Unit of measure $\mu \mathrm{g} / \mathrm{m}^{3}$ & IfcCeiling \\
VOCsEmissionCAM & CAM limit of the quantity of VOCs & emissions for elements. Unit of measure \\
& $\mu \mathrm{g} / \mathrm{m}^{3}$ & $\begin{array}{c}\text { IfcMaterial, IfcWall, IfcSlab, } \\
\text { IfcCeiling }\end{array}$ \\
\hline
\end{tabular}

Table 3. "Pset_SpaceIndoorAirQualityRequirements" and the parameters that compose it.

\begin{tabular}{|c|c|c|}
\hline Parameter Name & Parameter Description & Entities \\
\hline SpaceVOCs & VOCs presence inside the space. Unit of measure $\mu \mathrm{g} / \mathrm{m}^{3}$ & IfcSpace \\
\hline WallCoveringVOCsTestChamber & $\begin{array}{l}\text { VOCs Test Chamber Concentration of wall finish inside the } \\
\text { space. Unit of measure } \mu \mathrm{g} / \mathrm{m}^{3}\end{array}$ & IfcSpace \\
\hline FloorCoveringVOCsTestChamber & $\begin{array}{l}\text { VOCs Test Chamber Concentration of floor finish inside } \\
\text { the space. Unit of measure } \mu \mathrm{g} / \mathrm{m}^{3}\end{array}$ & IfcSpace \\
\hline CeilingCoveringVOCsTestChamber & $\begin{array}{l}\text { VOCs Test Chamber Concentration of ceiling finish inside } \\
\text { the space. Unit of measure } \mu \mathrm{g} / \mathrm{m}^{3}\end{array}$ & IfcSpace \\
\hline WallCoveringVOCs & $\begin{array}{l}\text { VOCs Concentration of wall finish inside the space. } \\
\text { Unit of measure } \mu \mathrm{g} / \mathrm{m}^{3}\end{array}$ & IfcSpace \\
\hline FloorCoveringVOCs & $\begin{array}{l}\text { VOCs Concentration of floor finish inside the space. } \\
\text { Unit of measure } \mu \mathrm{g} / \mathrm{m}^{3}\end{array}$ & IfcSpace \\
\hline CeilingCoveringVOCs & $\begin{array}{l}\text { VOCs Concentration of ceiling finish inside the space. } \\
\text { Unit of measure } \mu \mathrm{g} / \mathrm{m}^{3}\end{array}$ & IfcSpace \\
\hline
\end{tabular}

\subsection{Automatized Process to Apply the Parameters to BIM Elements}

The parameters are inserted into the BIM model, developed in the Autodesk Revit environment, through the use of "Shared Parameters". To speed up and automate the process as much as possible, the free add-in "ParaManager" developed by DiRoots was used [42].

ParaManager is an add-in for Revit that allows the management of the parameters from the model for individual families. It allows to create, modify, connect, transfer, export, and standardise all Revit parameters for reuse on current and future projects. It is chosen to operate with this tool because it allows assigning several parameters to multiple categories of BIM elements simultaneously while using the Revit basic commands can be assigned only one shared parameter at a time making this a very long, repetitive, and error-prone work. 
After creating the information structure of all the parameters necessary for the analysis of the VOC emission within the BIM model, they must be filled in with the appropriate values. Therefore, a shared spreadsheet was set up in the cloud with all project stakeholders thanks to the use of Google Spreadsheet. The spreadsheet was created by extrapolating the information directly from the BIM model by creating two separate sheets for compiling the values. To extract the information from the model and insert it into a spreadsheet, schedules have been set up within Autodesk Revit and then exported in ".txt" format with the "Export-> Report" command. The .txt file created was then opened in Excel for a table view and subsequently uploaded to the Google Spreadsheet cloud sharing platform.

Two levels of definition have been created:

1. Parameters to assign to the materials.

2. Parameters to assign to the rooms/spaces.

After the creation of the parameters and their compilation with the project values, there is the check of the correct insertion. Control takes place in three steps:

1. Checking the current presence of the shared parameters assigned to the correct category.

2. Check for the presence of a compiled value within the shared parameters created.

3. Checking the validity of the compiled values with the threshold values expressed by the CAM for the materials and a guide value, deriving from the analysis and critical reading of the IAGVs, for the rooms/spaces.

To implement this triple check, the free add-in "Autodesk BIM Interoperability Tools for Revit" and in particular the commands of the "Autodesk Model Checker for Revit" are used [43].

By creating a CheckSet in Autodesk Revit Model Checker specifically for the analysis of VOC emissions it is possible to save it in XML format and make it available to the whole scientific community as certain institutions did, such as "The Ohio State University" [44].

\subsection{BIM to Integrate VOC Prediction Model}

Estimating the concentration of pollutants in a confined environment can be achieved with different types of numerical models generically capable of considering the sources of the pollutant and the fluid dynamic conditions of the environment. This work considers and integrates a box-model using a mass balance approach within the BIM process. This type of model, often used for indoor environments [45-47], can calculate the concentration of a pollutant in the volume represented by the room under examination starting from a hypothesis of complete mixing (box-model), namely assuming a homogeneous distribution of the concentration in the volume itself.

For the purposes of this work, a specific numerical model, capable of estimating the concentration of VOC established in indoor environments as a result of the emissions due to building materials, has been developed ad-hoc. The numerical model developed as part of the Project "BIM4H\&W: BIM for Health and Wellbeing" (POR FESR LAZIO 2014/2020-Integrated projects) and presented in another contribution by the authors in this special issue, it calculates the temporal variation of VOC concentration as a function of ventilation conditions.

To provide designers with a tool for analysing and comparing design solutions, in a first instance, relationships suitable for integration into the BIM process were also extrapolated from the aforementioned numerical model. The criterion used for this operation was that of maximum simplification of the relationships themselves and the use of parameters available in BIM modelling. The developed numerical model estimates the concentration of VOC in the indoor environment through Equation (1):

$$
V \frac{d C_{\text {ind }}}{d t}=A E R \cdot V \cdot C_{\text {vent }}-A E R \cdot V \cdot C_{\text {ind }}+S
$$

where $\mathrm{V}\left[\mathrm{m}^{3}\right]$ represents the volume of the room considered, $C_{\text {ind }}\left[\mu \mathrm{g} / \mathrm{m}^{3}\right]$ represents the VOC concentrations in the indoor environment, AER $\left[h^{-1}\right]$ represents the air exchange rate, $C_{v e n t}\left[\mu \mathrm{g} / \mathrm{m}^{3}\right]$ 
represents the VOC concentration in the ventilation air, and S $[\mu \mathrm{g} / \mathrm{h}]$ represents the hourly VOC flow rate of the sources inside the room.

Wanting to estimate only the contribution to the concentration due to the materials and considering the emissions due to them to be constant over time, a hypothesis that can be considered plausible for materials laid for more than 28 days, the (1) becomes:

$$
\frac{d C_{i n d}}{d t}=\frac{S}{V}-A E R \cdot C_{i n d}
$$

The (2) allows to obtain the asymptotic value of the concentration that is reached in the indoor environment for certain ventilation conditions, that is:

$$
C_{\text {ind }}=\frac{S}{V \cdot A E R}
$$

This Equation (3) expresses the relationship between the VOC flow rate released into the room and the ventilation flow rate. The hourly flow thus considered is equivalent to the emission capacity of the material over time (ER), defined by the EN16515 standard [48,49].

The aforementioned standard defines the method for estimating the emissions of the various materials following tests carried out in the "chamber test". In particular, the emissive capacity of the material, the emission rate (ER) $[\mu \mathrm{g} / \mathrm{h}]$, is expressed as a function of the concentration, $C_{C H}\left[\mathrm{mg} / \mathrm{m}^{3}\right]$, that is established in the air inside the "chamber" with a volume equal to $1 \mathrm{~m}^{3}$ with an Air Exchange Rate, AER [1/h] equal to 0.5 considering $1 \mathrm{~m}^{2}$ of material surface (4):

$$
E R[\mu \mathrm{g} / \mathrm{h}]=C_{C H}\left[\mu \mathrm{g} / \mathrm{m}^{3}\right] \cdot 1\left[\mathrm{~m}^{3}\right] \cdot 0.5[1 / \mathrm{h}]
$$

Starting from this parameter (4) it is possible to define the area-specific emission capacity or area-specific emission rate, SER:

$$
\operatorname{SER}\left[\mu \mathrm{g} /\left(\mathrm{m}^{2} \mathrm{~h}\right)\right]=E R[\mu \mathrm{g} / \mathrm{h}] / 1\left[\mathrm{~m}^{2}\right]
$$

Using this last parameter (5), the Equation (6) was defined as capable of estimating the concentration of VOC, $C_{a}$, which is reached in a room volume $V_{a}$, under steady ventilation conditions determined by the $A E R_{a}$, due to the emissions of an internal source of VOC, consisting of a material, characterised by $S E R_{a}$, and distributed over the surface area $A_{s}$ :

$$
C_{a}=\frac{S E R_{a} \cdot A_{s}}{A E R_{a} \cdot V_{a}}
$$

This report (6) applies what is defined in the EN 16,515 standard relating to ideal reference room, to a real room, in which it is considered a loading factor, $L_{a}$, defined by the ratio between the $\mathrm{m}^{2}$ on which the material is present and the $\mathrm{m}^{3}$ of the volume of the room considered, that is (7):

$$
L_{a}=\frac{A_{s}}{V_{a}}
$$

The Equation (6) can be rewritten as (8):

$$
C_{a}=\frac{S E R_{a} \cdot L_{a}}{A E R_{a}}
$$

where:

- $S E R_{a}$ : area-specific emission rate of the considered material.

- $A_{s}$ : areal extension of the source characterised by the specific SER.

- $V_{a}$ : volume of the room. 
- $A E R_{a}$ : air exchange rate.

The Equation (8) can also be written as follows (9):

$$
C_{a}\left[\mu \mathrm{g} / \mathrm{m}^{3}\right]=\frac{\left(C_{C H}\left[\mu \mathrm{g} / \mathrm{m}^{3}\right] \cdot 1\left[\mathrm{~m}^{3}\right] \cdot 0.5[1 / \mathrm{h}] / 1\left[\mathrm{~m}^{2}\right]\right) \cdot A_{s}\left[\mathrm{~m}^{2}\right]}{A E R_{a}[1 / \mathrm{h}] \cdot V_{a}\left[\mathrm{~m}^{3}\right]}
$$

This last relationship allows us to calculate the concentration in the room, with defined ventilation, with the emission data of the material as estimated in the test chamber available.

The numerical model thus developed was implemented within the BIM model, and applied to all the finishes of the rooms/spaces. All the parameters used in the Equation (9) can be obtained from a BIM modelling developed for this purpose.

In Table 4, the parameters of Equation (9) and its transposition in the formulas (10) for inclusion in the BIM environment are explained.

$$
\begin{aligned}
\text { WallCoveringVOCs } & =\frac{\text { WallCoveringVOCSTestChamber } \cdot 0.5 \cdot \text { NetWallArea }}{\text { MechanicalVentilationRate-NetVolume }} \\
\text { FloorCoveringVOCs } & =\frac{\text { FloorCoveringVOCsTestChamber } \cdot 0.5 \cdot \text { NetFloorArea }}{\text { MechanicalVentilationRate-NetVolume }} \\
\text { CeilingCoveringVOCS } & =\frac{\text { CeilingCoveringVOCSTestChamber } 0.5 \cdot \text { NetCeilingArea }}{\text { MechanicalVentilationRate.NetVolume }}
\end{aligned}
$$

\begin{tabular}{|c|c|c|}
\hline Parameter Name & & Parameter Explanation \\
\hline WallCoveringVOCs & $C_{a}$ & $\begin{array}{l}\text { VOC concentration that is reached in the room due to the } \\
\text { contribution of the wall finishes. }\end{array}$ \\
\hline FloorCoveringVOCs & $C_{a}$ & $\begin{array}{l}\text { VOC concentration that is reached in the room due to the } \\
\text { contribution of floor finishes. }\end{array}$ \\
\hline CeilingCoveringVOCs & $C_{a}$ & $\begin{array}{c}\text { VOC concentration that is reached in the room due to the } \\
\text { contribution of the false ceiling finishes. }\end{array}$ \\
\hline WallCoveringVOCsTestChamber & $\mathrm{C}_{\mathrm{CH}}$ & $\begin{array}{l}\text { the concentration of VOCs emitted by the finishing material of the } \\
\text { walls of the room calculated in the test chamber according to } \\
\text { EN16515 standard. } 1\end{array}$ \\
\hline FloorCoveringVOCsTestChamber & $\mathrm{C}_{\mathrm{CH}}$ & $\begin{array}{l}\text { the concentration of VOCs emitted by the finishing material of the } \\
\text { floors of the room calculated in the test chamber according to } \\
\text { EN16515 standard. }\end{array}$ \\
\hline CeilingCoveringVOCsTestChamber & $\mathrm{C}_{\mathrm{CH}}$ & $\begin{array}{l}\text { the concentration of VOCs emitted by the finishing material of the } \\
\text { ceilings of the room calculated in the test chamber according to } \\
\text { EN16515 standard. }{ }^{1}\end{array}$ \\
\hline & 0.5 & air exchange rate of the test chamber. \\
\hline NetWallArea & $A_{S}$ & $\begin{array}{l}\text { the net area of the walls in the room where the emissive material is } \\
\text { present, characterised by the specific } C_{C H} \text {. This value does not } \\
\text { include the area of windows, doors, glass walls and all finishes } \\
\text { that are composed of non-emissive material. }{ }^{2}\end{array}$ \\
\hline NetFloorArea & $A_{S}$ & $\begin{array}{l}\text { the net area of the floors present in the room where the emissive } \\
\text { material is present, characterised by the specific } C_{C H}{ }^{2}\end{array}$ \\
\hline NetCeilingArea & $A_{s}$ & $\begin{array}{l}\text { the net area of the ceilings present in the room where the emissive } \\
\text { material is present, characterised by the specific } C_{\mathrm{CH}}{ }^{2}\end{array}$ \\
\hline MechanicalVentilationRate & $A E R_{a}$ & $\begin{array}{l}\text { the volumes of air changes expressed in } 1 / \mathrm{h} \text { which are established } \\
\text { by the designer for each room based on the intended use. }\end{array}$ \\
\hline NetVolume & $V_{a}$ & $\begin{array}{c}\text { walls and the volumes of any structures within the room such as } \\
\text { pillars or shafts. }\end{array}$ \\
\hline
\end{tabular}

Table 4. Explanation of parameters and transposition of the Equation (9) within the BIM model.

\footnotetext{
${ }^{1}$ This is a value that must be obtained from the technical data sheets provided by the manufacturer; ${ }^{2}$ To obtain this area, the designer must refer to the quantities that are automatically calculated through the free add-in "Roombook Areabook Buildingbook for Revit" or, only in the case of floors and ceilings, simply using the floor area of the room automatically calculated in Autodesk Revit.
} 
Summing the VOC concentration due to the contribution of all the finishes relating to a room is obtained:

$$
\text { SpaceVOCs }=\text { WallCoveringVOCs }+ \text { FloorCoveringVOCs }+ \text { CeilingCoveringVOCs }
$$

where SpaceVOCs $\left(C_{a}\right)$ represents VOC concentration that is reached in the room due to the contribution of all the present finishes.

A Revit schedule was created to use the numerical model for calculating the VOC concentration due to the emission of materials directly within the BIM design software, in this case, Autodesk Revit.

\subsection{Model Checker in the BIM Process to Verify Indoor TVOC Emission Related to IAGVS}

For the verification of the threshold values of the VOC concentrations due to the materials for every single room/space of the BIM model, the following formula must be verified:

$$
\text { SpaceVOCs }<50 \mu \mathrm{g} / \mathrm{m}^{3}
$$

The limit value $50 \mu \mathrm{g} / \mathrm{m}^{3}$ was set based on simulations carried out with the box-model using three types of low-emissivity materials: One used in the case study and two others selected from scientific literature [50]. The emission values of these materials are, respectively: $7.1 \mu \mathrm{g} / \mathrm{m}^{3} ; 50 \mu \mathrm{g} / \mathrm{m}^{3} ; 240 \mu \mathrm{g} / \mathrm{m}^{3}$. These values were compared with the threshold values established by the environmental sustainability certification protocol BREEAM [51] (Basic level $1000 \mu \mathrm{g} / \mathrm{m}^{3}$; Exemplary Level $300 \mu \mathrm{g} / \mathrm{m}^{3}$ ) and with the limit value defined by the Italian CAM $\left(1500 \mu \mathrm{g} / \mathrm{m}^{3}\right)$. These emission values were applied in the numerical mass balance model developed and considering the reference room defined by the EN 16,515 standard to evaluate the concertation of TVOC in an indoor environment. The concentration values thus obtained were compared with the IAGVs defined by Portugal, equal to the value of $600 \mu \mathrm{g} / \mathrm{m}^{3}$. In light of the results obtained, it was decided to set the limit on the value of $50 \mu \mathrm{g} / \mathrm{m}^{3}$ as a precautionary threshold. This reasoning is because this threshold only considers the concentration of TVOC due to building materials and therefore useful for design purposes, to which the contributions of outdoor air, people, furniture, and cleaning products are added. It was therefore decided to settle on a value of approximately $10 \%$ of the considered IAGV.

The verification of the parameter, and therefore of the VOC emission to the defined threshold value, is implemented through the creation of a check rule (CheckSet) with "Autodesk Model Checker".

\subsection{Case Study: New Expansion of CNR in Pisa, Italy}

The case study selected to develop the proposed workflow and the integration between IAQ and BIM is a recent project by RI.EL.CO IMPIANTI SRL, with which the "Sapienza" University of Rome carried out the research project in partnership of effective collaboration. The building chosen is the new headquarters of the Institute of Informatics and Telematics (IIT), which is part of the Research Area of the C.N.R., in Pisa (IT). The project developed with the raising of a portion of an existing building, defined on a regular modular grid and with a " $\mathrm{T}$ "-shaped planimetric development, is divided into three buildings for a total of about $1400 \mathrm{~m}^{2}$ : A (the west wing of the " $\mathrm{T}$ "); B (central building), and C (the east wing of " $\mathrm{T}$ "). The research project and the contents of this paper focus on building $\mathrm{A}$ as a case study (Figure 2). Construction of the building was completed in 2020, and it was inaugurated in February of this year. The preliminary design of the building is by Eng. Ottavio Zirilli (CNR), the executive project was handled by RIELCO Srl (Project Leader Eng. Carmine Rinaldi).

The structure is set on a single floor and built-in CLT (cross laminated timber). The building has a height of about $5.13 \mathrm{~m}$ on average compared to the elevation of the existing building roof (quote $+9.00 \mathrm{~m}$ ), with a roof slope of $5 \%$. The design choices were strongly directed towards a high level of prefabrication and quality control, particularly attentive to both individual building components and overall performance. The internal non-load-bearing divisions are made of double plasterboard plate with interposed insulating material. Low-emissivity materials have been chosen for 
the gypsum panels, thermal and acoustic insulators, and all components. The stoneware floors and metal ceilings also comply with the ISO 14,021 standard and the sustainability principles of the absence of hazardous emissions and also comply with the requirements of the LEED, BREEAM, and ITACA environmental certification protocols. The window frames are thermal break and in wood-aluminium with mechanical corner joint without the use of adhesives; other seals are made with neutral silicone. In all three buildings, the central distribution is achieved through the main corridor divided from the offices by a glass partition wall. In general, all finishing materials such as paints, fillers, and sealants were chosen according to the sustainability principles suggested by the CAM.

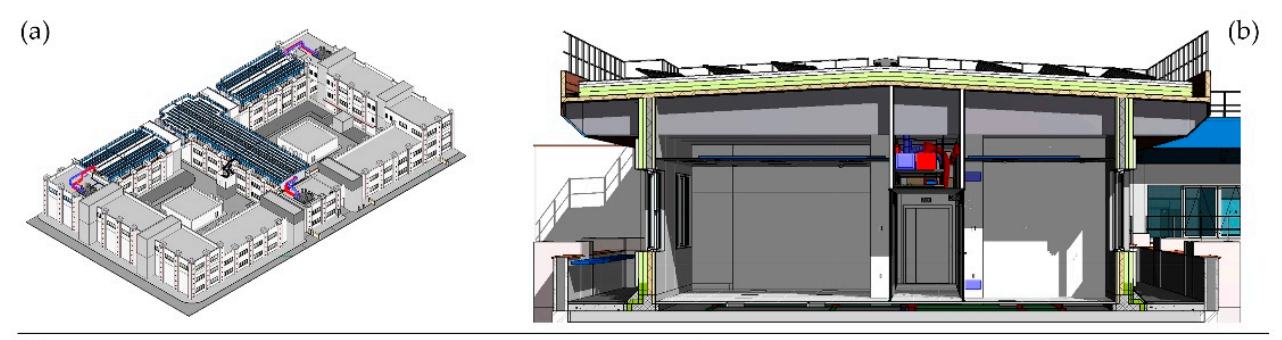

(c)
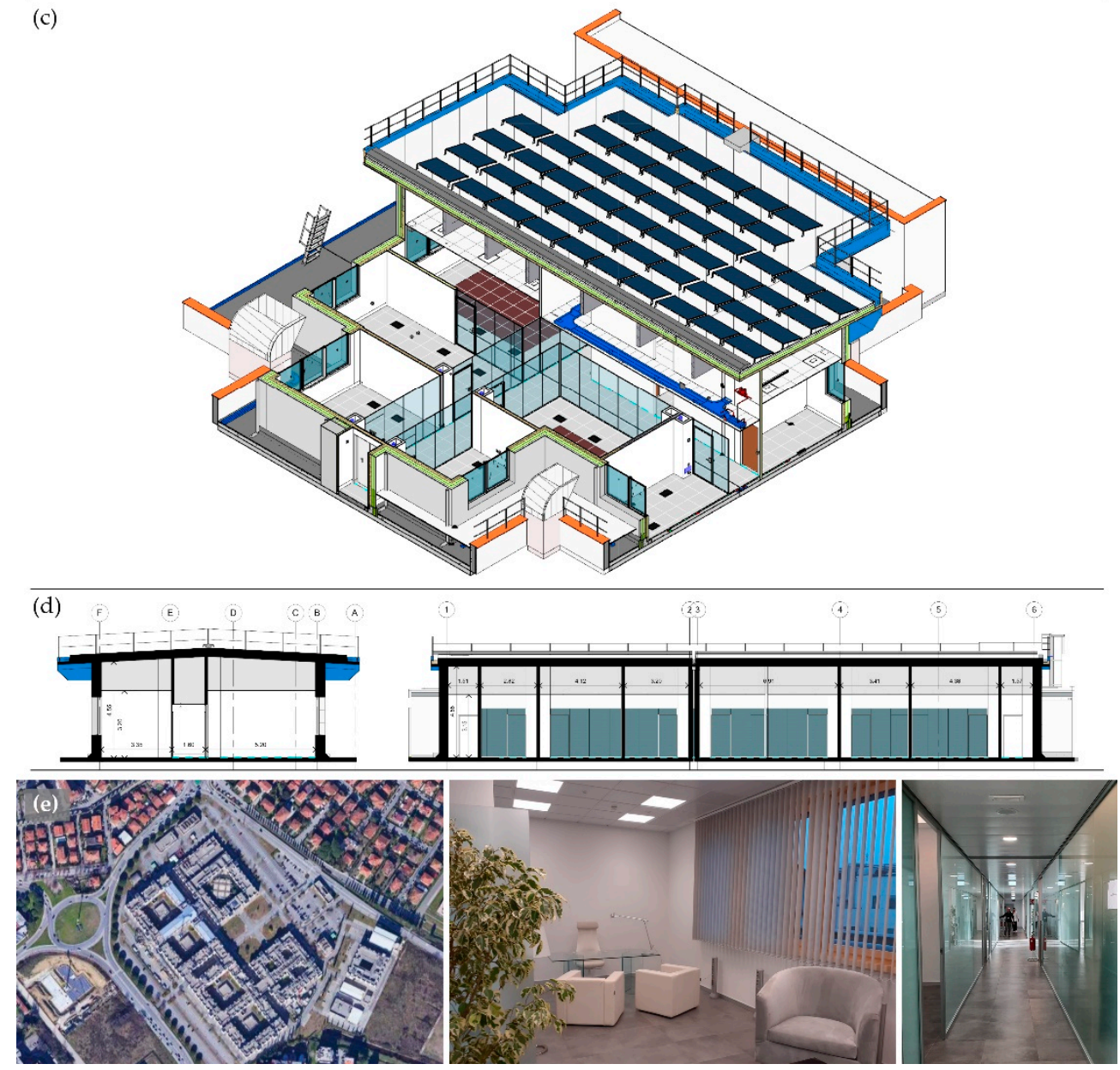

Figure 2. (a) Axonometry of the existing building and of the elevation; (b) perspective section with construction details; (c) isometric section with construction details; (d) sections of building A; (e) photos of the building: an area view from google maps, the interior of an office, and the main corridor.

The HVAC system contains all-air and is separated for each of the three buildings where heating, cooling, humidity, and air quality control are carried out through a centralised aeraulic system with variable flow and heat recovery. Even the air distribution channels have been designed with 
particular attention to IAQ and made with sandwich panels consisting of an insulating layer of rigid polyurethane foam covered on the outside with embossed aluminium sheets and on the inside with smooth aluminium sheets for better thermal insulation and good hygiene. Inside each room, the air is introduced through a plenum and then reaches the indoor environment through micro-perforated panels in the false ceiling; while the air intake is performed by a series of outlet vents placed on technical shafts on the side of the entrance doors. The air recovery takes place according to two configurations: In the summer, the air is drawn in by vents located at $2.6 \mathrm{~m}$ from the floor, while in winter, by those placed at $0.15 \mathrm{~m}$. The technological solutions implemented within the mechanical systems aim to improve IAQ and have specifically been increased by the installation of additional class G4 and class F7 filters, by a plasma reactor in the upstream section of the distribution channels and by UVc germicidal lamp inside each air diffusion plenum.

In particular, building $\mathrm{A}$, chosen as a case study, consists of eight offices, a meeting and conference room, a storage room, an archive, and the toilets (Figure 3). The graphic drawings shown were developed by RIELCO IMPIANTI S.r.l. and extracts from the BIM model of the building.

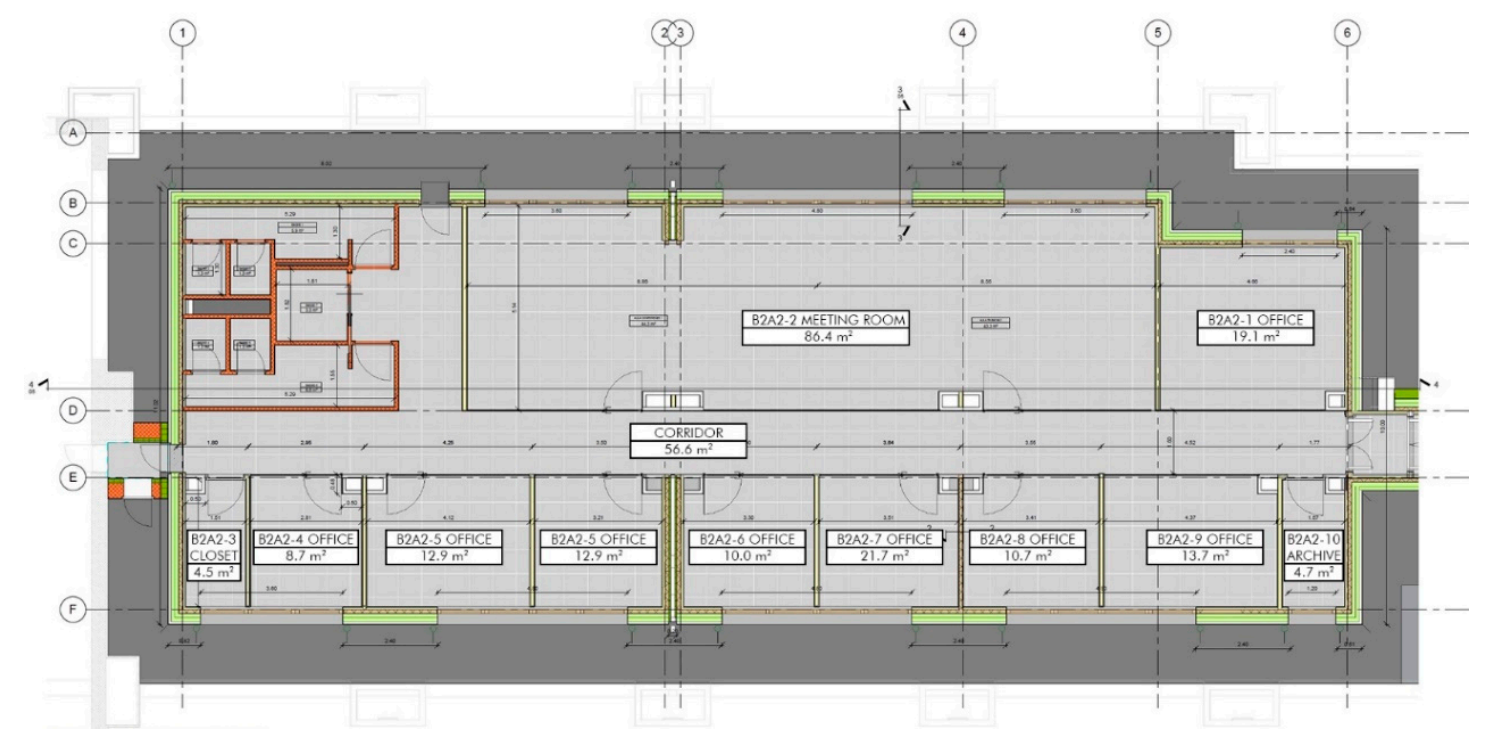

Figure 3. Plan of the case study: Building A, the new expansion of the CNR of Pisa.

\section{Results}

The following section shows the results of research, divided into four areas: (i) IAQ parameters to be implemented in BIM process Revit-based and compliant with IFC schema; (ii) automatised process to apply the shared parameters to BIM elements; (iii) BIM to integrate VOC prediction model for BIM elements in rooms category; (iv) model checker in BIM process to verify indoor VOC emission related to IAGVs.

\subsection{IAQ Parameters to Be Implemented in the BIM Process Revit-Based and Compliant with IFC Schema}

Once the parameters necessary for the implementation of the analysis of VOC emission workflow have been elaborated, as consistent as possible with the IFC scheme as explained in the methods section, we proceeded with their implementation in the BIM environment, within the model developed with BIM Authoring Autodesk Revit. In Autodesk Revit, the procedure for inserting parameters to BIM elements that can be reused on different projects involves the use of the "shared parameters" command. It is possible to create a list of "shared parameters" written within a file in .txt format that can subsequently be used to insert the same parameter structure within a BIM model or a BIM element (parametric family). 
Autodesk provides free to its users an already pre-compiled txt file of "shared parameters", containing all the IFC standard parameters, called "Shared Parameters IFC-RevitIFCBuiltIn_ALL.txt" [52]. It is also possible to create a self-customised .txt file but following the formatting specifications of the IFC parameters. By subsequently assigning these "shared parameters" to the correct Revit family categories within the "IFC parameters" parameter group, it is possible to export a file in IFC format from Autodesk Revit that has the parameter consistent with the IFC scheme. However, it is necessary to underline that two "shared parameters" that have been inserted in a BIM model developed in Autodesk Revit using two .txt files created by two different authors cannot be considered the same by the Revit software even if they have exactly the same name.

Then, the research deals with the creation of a new "shared parameters" .txt file specific for the VOC emission analysis workflow; this file will be named "Shared Parameters-BIM4H\&W.txt" (Figure 4). The following corrective actions have been implemented to resolve some critical issues relating to the entry of parameters for the openBIM standard in the Revit environment:

1. A new "shared parameter" is created with the name "MechanicalVentilationRate" and set as the data type "Number";

2. The "IfcQtyNetWallArea", "IfcQtyNetCeilingArea" and "IfcQtyNetVolume" parameters in the official txt file "IFC Shared Parameters-RevitIFCBuiltIn_ALL.txt" are copied into the new file "Shared Parameters-BIM4H \& W.txt" paying particular attention to copy the same GUID code (the unique ID consisting of 36 characters) of the official "shared parameter";

3. No further "shared parameter" called "NetFloorArea" will be added, but the "Area" parameter of the "Rooms" category already present by default in Autodesk Revit will be used.

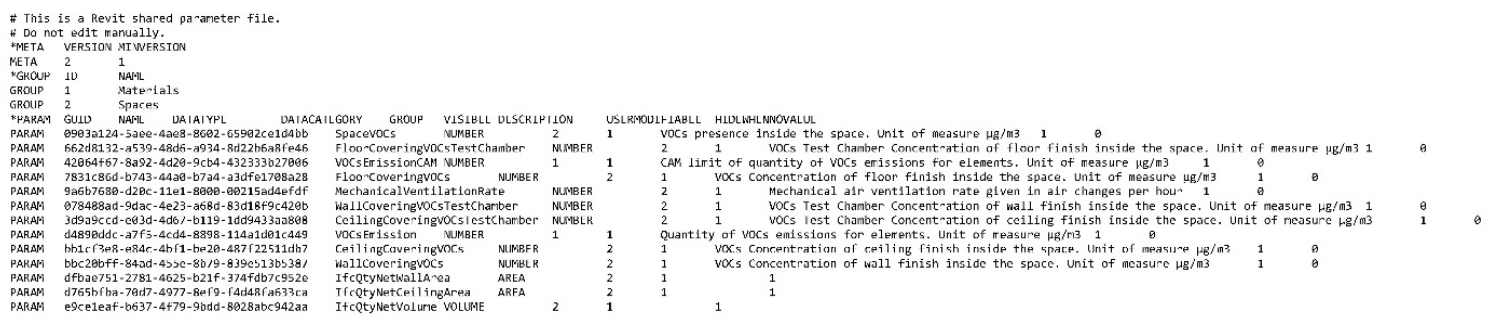

Figure 4. File "Shared Parameters-BIM4H\&W.txt".

The above critical issues are dealt with in detail in the discussion section (see Section 4.2). The .txt file of the "shared parameters" "Shared Parameters-BIM4H \& W.txt" is therefore composed of the parameters listed in Table 5.

Table 5. Shared parameters present in the "Shared Parameters-BIM4H\&W.txt" file.

\begin{tabular}{|c|c|c|c|c|}
\hline Parameter Name & $\begin{array}{l}\text { Data } \\
\text { Type }\end{array}$ & $\begin{array}{l}\text { Group } \\
\text { Name }\end{array}$ & Description & $\begin{array}{c}\text { Already Present in } \\
\text { "RevitIFCBuiltIn_ALL.txt" }\end{array}$ \\
\hline VOCsEmission & Number & Materials & $\begin{array}{l}\text { Quantity of VOCs emissions for } \\
\text { elements. Unit of measure } \mu \mathrm{g} / \mathrm{m} 3\end{array}$ & No \\
\hline VOCsEmissionCAM & Number & Materials & $\begin{array}{c}\text { CAM limit of the quantity of VOCs } \\
\text { emissions for elements. Unit of } \\
\text { measure } \mu \mathrm{g} / \mathrm{m} 3\end{array}$ & No \\
\hline WallCoveringVOCsTestChamber & Number & Spaces & $\begin{array}{c}\text { VOCs Test Chamber Concentration } \\
\text { of wall finish inside the space. Unit } \\
\text { of measure } \mu \mathrm{g} / \mathrm{m} 3\end{array}$ & No \\
\hline FloorCoveringVOCsTestChamber & Number & Spaces & $\begin{array}{l}\text { VOCs Test Chamber Concentration } \\
\text { of floor finish inside the space. Unit } \\
\text { of measure } \mu \mathrm{g} / \mathrm{m} 3\end{array}$ & No \\
\hline
\end{tabular}


Table 5. Cont.

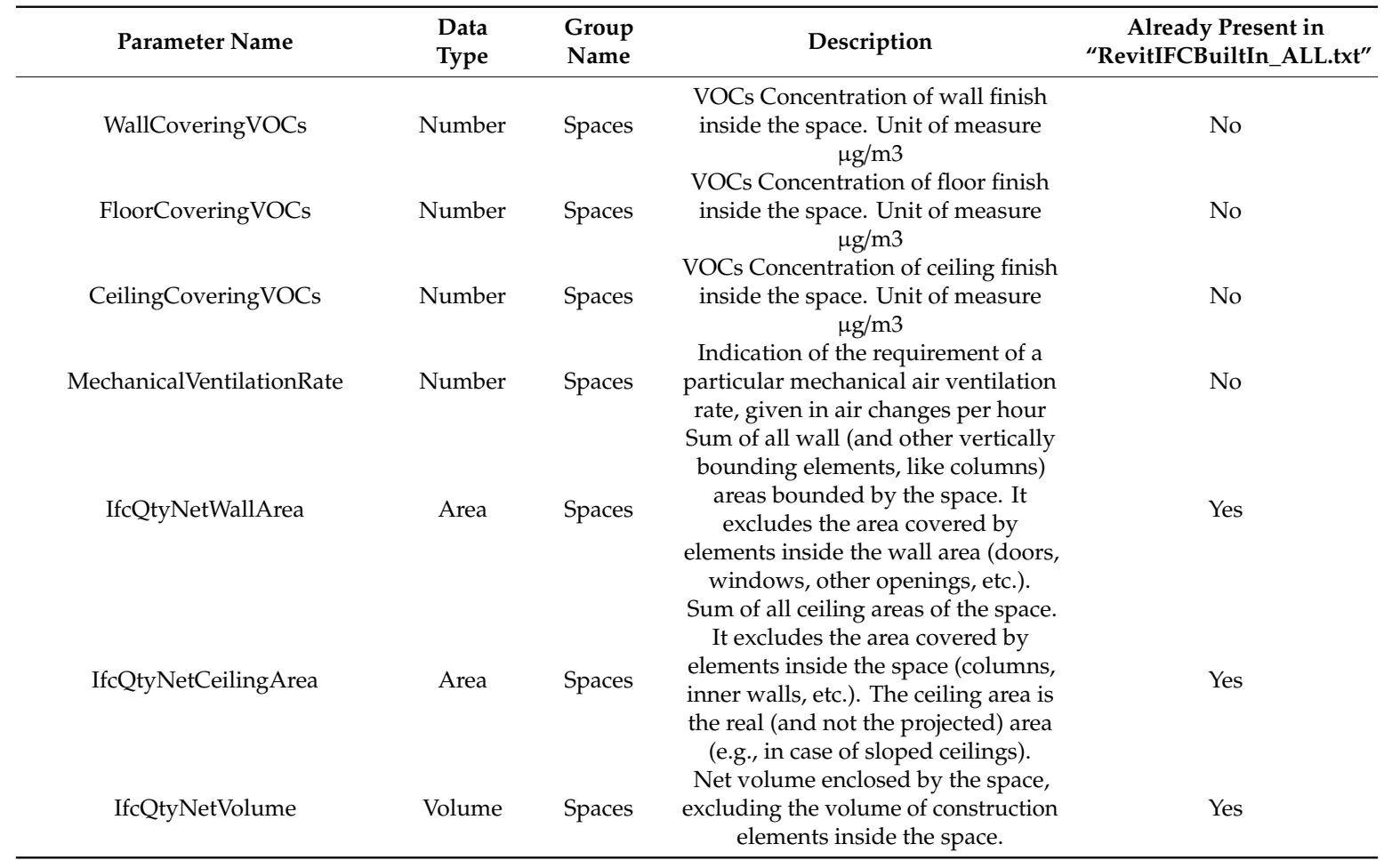

\subsection{Automatised Process to Apply the Shared Parameters to BIM Elements}

\subsubsection{Automated Parameter Entry}

The process of entering the shared parameters was automated through the use of the ParaManager add-in. The use of this tool has brought the advantage of assigning numerous parameters to multiple categories of BIM elements simultaneously (Figure 5), reducing the risk of error in a manual procedure made by the operator. Furthermore, it was possible to create and save groups of categories of BIM elements to which shared parameters can be assigned (Figure 6).

A spreadsheet was created to optimise the process and to better manage the insertion of parameters. This sheet can then be reused to automatically recreate the same mapping in a future project. The parameters entered in the spreadsheet (Table 6) are the same that are also present in the "Shared Parameters-BIM4H\&W.txt" file (Figure 4).

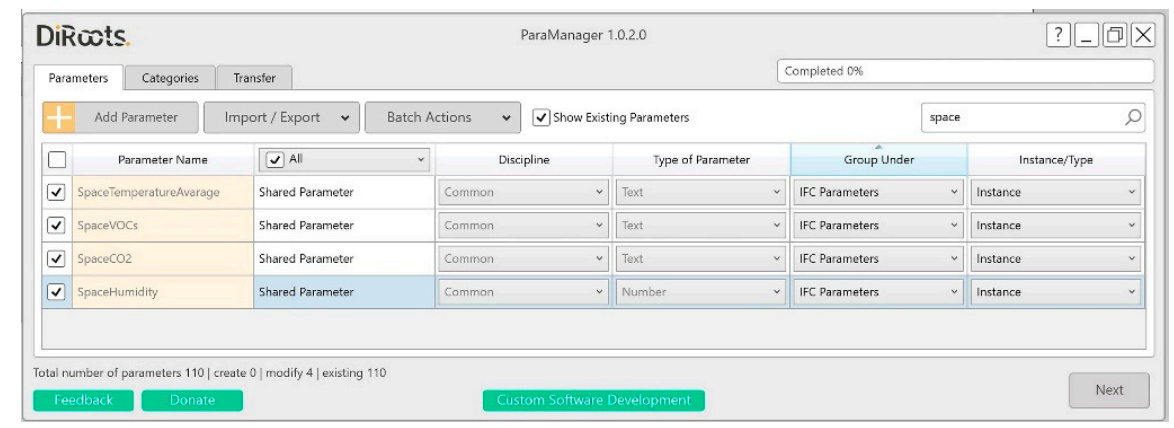

Figure 5. Creating multiple shared parameters at the same time within ParaManager add-in. 


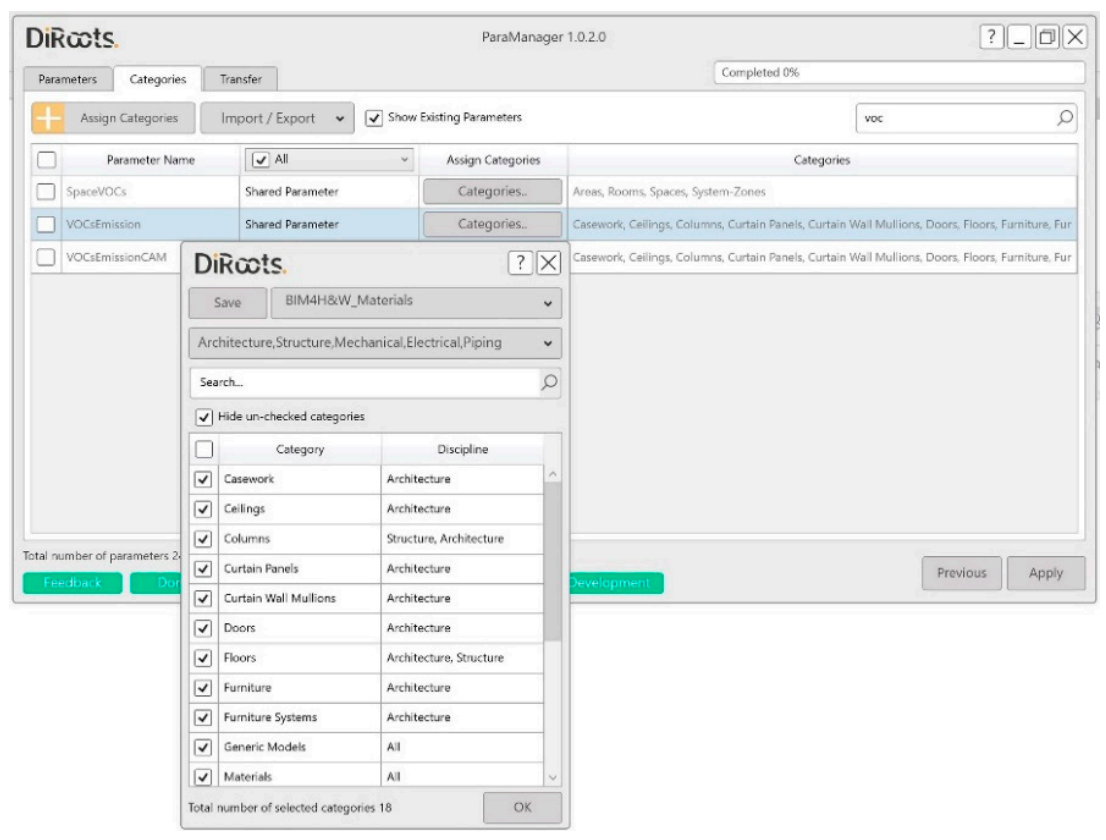

Figure 6. Creation of the "BIM4H\&W_Materials" category group that allows us to assign the shared parameters relating to the categories of Materials more quickly within ParaManager add-in.

Table 6. Parameters included in the Autodesk Revit BIM model through ParaManager.

\begin{tabular}{|c|c|c|c|c|c|}
\hline \multirow{2}{*}{$\begin{array}{c}\text { Parameter Name } \\
\text { VOCsEmission }\end{array}$} & \multicolumn{2}{|c|}{ Discipline Type of Parameter } & \multirow{2}{*}{$\begin{array}{c}\text { Group } \\
\text { IFC Parameters }\end{array}$} & \multirow{2}{*}{$\begin{array}{c}\text { Instance/Type } \\
\text { Instance }\end{array}$} & \multirow{2}{*}{$\begin{array}{c}\text { Categories } \\
(2)\end{array}$} \\
\hline & Common & Number & & & \\
\hline VOCsEmissionCAM & Common & Number & IFC Parameters & Instance & (2) \\
\hline SpaceVOCs & Common & Number & IFC Parameters & Instance & (1) \\
\hline WallCoveringVOCsTestChamber & Common & Number & IFC Parameters & Instance & (1) \\
\hline FloorCoveringVOCsTestChamber & Common & Number & IFC Parameters & Instance & (1) \\
\hline WallCoveringVOCs & Common & Number & IFC Parameters & Instance & (1) \\
\hline FloorCoveringVOCs & Common & Number & IFC Parameters & Instance & (1) \\
\hline CeilingCoveringVOCs & Common & Number & IFC Parameters & Instance & (1) \\
\hline MechanicalVentilationRate & Common & Integer & IFC Parameters & Instance & (1) \\
\hline IfcQtyNetWallArea & Common & Area & IFC Parameters & Instance & (1) \\
\hline IfcQtyNetCeilingArea & Common & Area & IFC Parameters & Instance & (1) \\
\hline
\end{tabular}

(1) Areas, Rooms, Spaces, System-Zones; (2) Casework, Ceilings, Columns, Curtain Panels, Curtain Wall Mullions, Doors, Floors, Furniture, Furniture Systems, Generic Models, Materials, Railings, Roofs, Stairs, Structural Columns, Structural Framing, Walls, Windows.

\subsubsection{Model Checking for the Material Parameters}

Thus, after the filling of the proper parameters, it is possible to apply the triple check, exposed in methodology (§ 2.2). A "Checkset" for appropriate presence, filling, and value in parameters (Figure 7) has been created in .xml format, a set of control rules, specific for the VOC emission analysis workflow.

The "BIM4H\&W.xml" file contains Checksets that can be used in all BIM models developed in Autodesk Revit and that have previously entered the shared parameters of the "Shared Parameters-BIM4H\&W.txt" file.

Containing all the necessary rules for the BIM4H\&W workflow, the Checkset is organised in sections, so the user can activate the controls step by step.

Sets of rules have been created within the section called "Materials" to control the parameters related to materials, so the user can click on the "Setup" command and decide to activate only the checks on materials (Figure 8). 


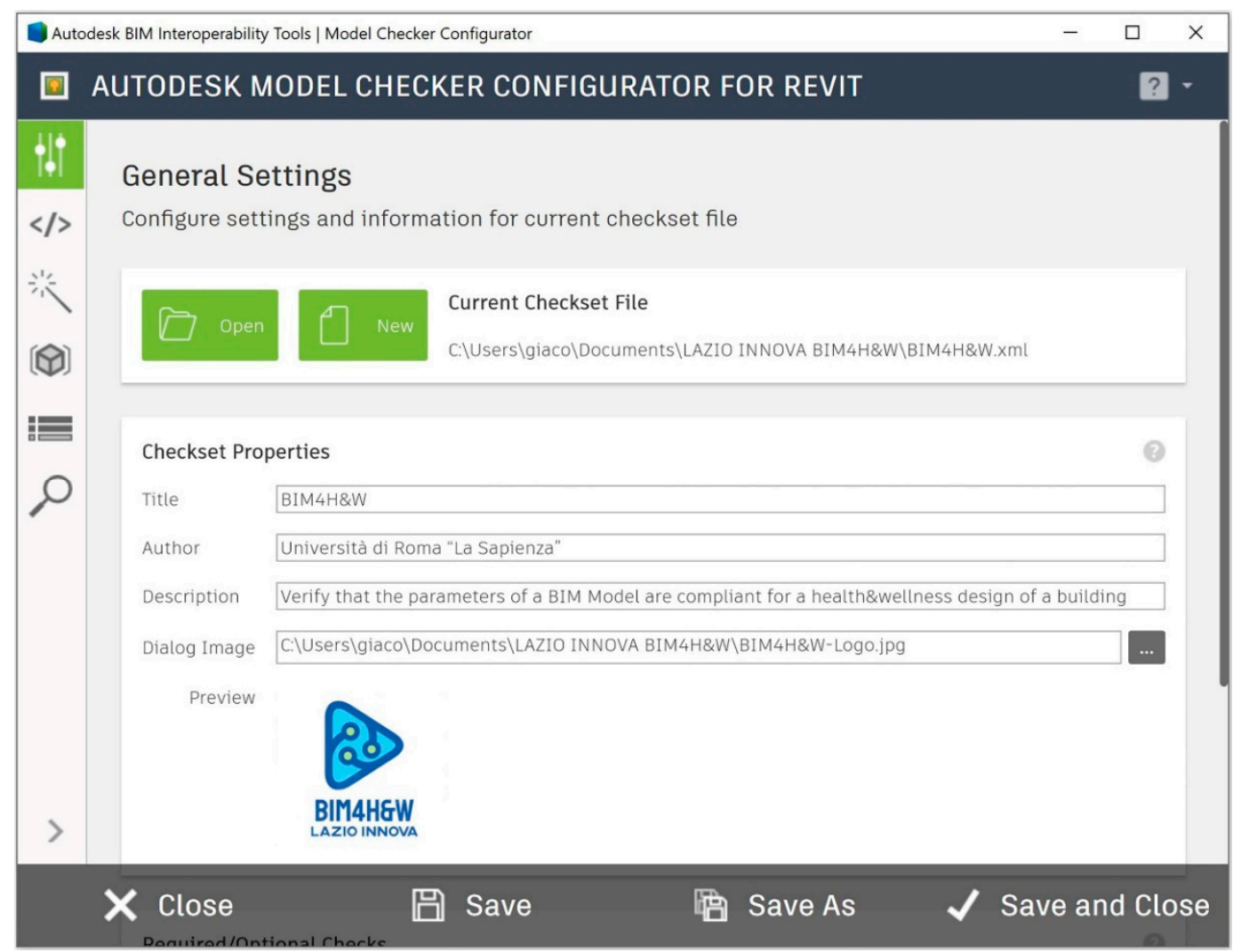

Figure 7. General settings of the checkset created specifically for the verification of the BIM4H\&W parameters.

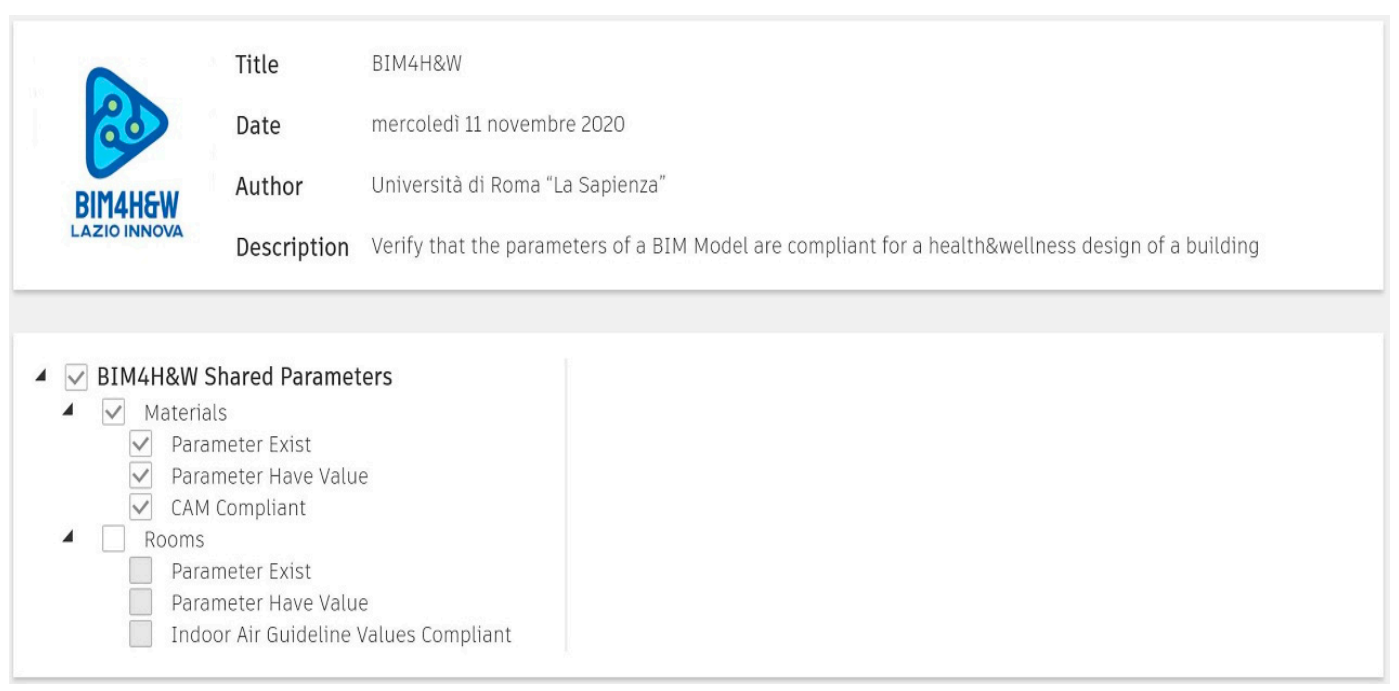

Figure 8. Activation of the control rules relating to the materials of the BIM model only.

The first rule verifies the actual existence in the model of the BIM4H\&W parameters assigned to the materials. The parameters that must be assigned to the materials are VOCsEmission and VOCsEmissionCAM. The second rule verifies the compilation with a value of the BIM4H\&W parameters assigned to the materials. The third rule verifies that the values of the pollutants emitted by the materials are within the limit established by the CAM (Criteri Ambientali Minimi).

Precisely for this reason, specific parameters have been included within the model that indicates the maximum emission limit of that material according to the CAM (VOCsEmissionCAM). 
Through the use of the Model Checking and the rules settled (Figure 10), it is possible to have immediate feedback not only on the correct insertion and compilation of the parameters but also on the design choices regarding the materials used that may not be consistent with the performance required by the CAM concerning polluting emissions.

(a)

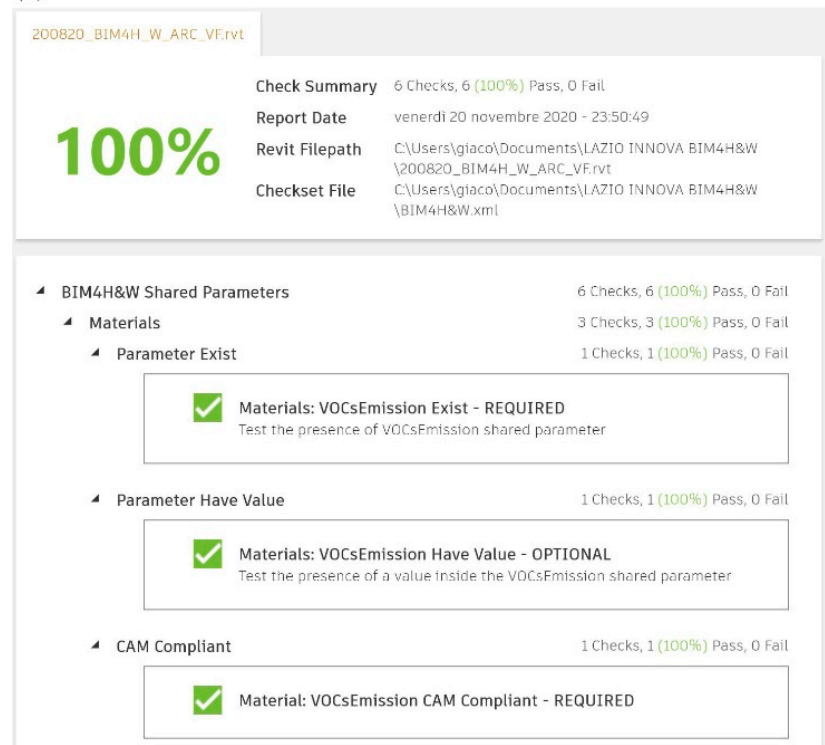

(b)

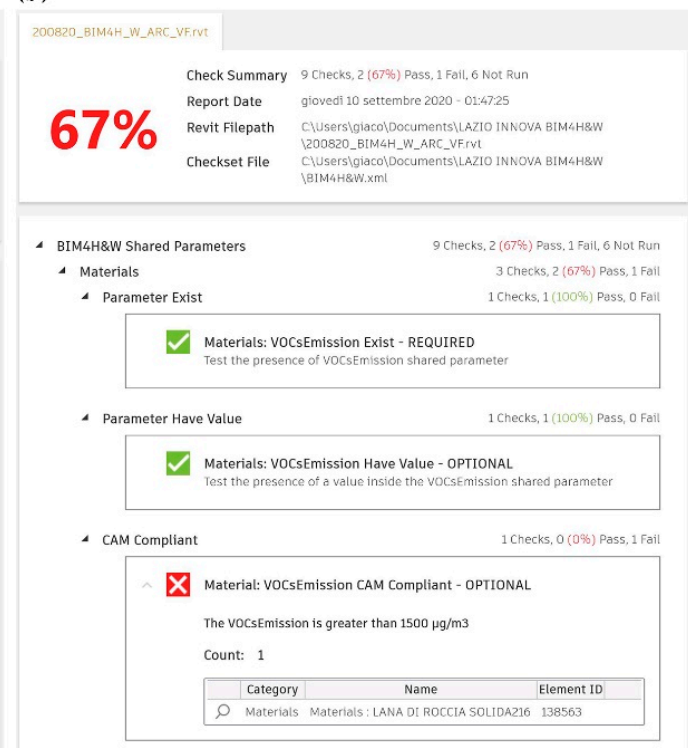

Figure 10. Screenshot of the report implemented on the BIM model in which all materials have VOC emission values below the limit identified in the CAM (a); Screenshot of the report implemented on the BIM model in which an example material exceeds the limit identified in the minimum environmental criteria (CAM) (b).

\subsection{BIM to Integrate VOC Prediction Model for BIM Elements in Rooms Category}

\subsubsection{Box-Model Using a Mass Balance Approach}

The box-model was applied to all the rooms in Building A, considering only the finishing material as an internal source, and estimating the asymptotic concentration that is reached for nominal or project ventilation conditions. Table 7 shows the values calculated with the box-model for the different rooms considered.

Table 7. VOC parameters and concentrations in the different rooms calculated with the box-model.

\begin{tabular}{|c|c|c|c|c|c|c|c|c|}
\hline \multicolumn{2}{|c|}{ Room } & \multirow{2}{*}{$\begin{array}{c}\text { Volume } \\
\mathrm{m}^{3}\end{array}$} & \multirow{2}{*}{$\begin{array}{c}\text { Air Flow } \\
\mathrm{m}^{3} / \mathrm{h}\end{array}$} & \multirow{2}{*}{$\begin{array}{c}\text { Air } \\
\text { Changes } \\
1 / \mathrm{h}\end{array}$} & \multirow{2}{*}{$\begin{array}{c}\text { Emissive } \\
\text { Surface }\end{array}$} & \multirow{2}{*}{$\begin{array}{c}\begin{array}{c}\text { Loading } \\
\text { Factor }\end{array} \\
\mathrm{m}^{2} / \mathrm{m}^{3}\end{array}$} & \multirow{2}{*}{$\begin{array}{c}\text { SER } \\
\mu g / \mathrm{m}^{2} \mathrm{~h}\end{array}$} & \multirow{2}{*}{$\begin{array}{c}\begin{array}{c}\text { VOC } \\
\text { Concentration }\end{array} \\
\mu \mathrm{g} / \mathrm{m}^{3}\end{array}$} \\
\hline & & & & & & & & \\
\hline B2A2-2 & meeting room & 280 & 950 & 3.4 & 65.72 & 0.235 & 3.55 & 0.24559 \\
\hline $\mathrm{B} 2 \mathrm{~A} 2-3$ & closet & 15 & 68 & 4.5 & 25.41 & 1.694 & 3.55 & 1.32655 \\
\hline B2A2-6 & office 7 & 33 & 115 & 3.5 & 28.45 & 0.862 & 3.55 & 0.87824 \\
\hline $\mathrm{B} 2 \mathrm{~A} 2-7$ & office 8-9 & 70 & 270 & 3.9 & 37.25 & 0.532 & 3.55 & 0.48977 \\
\hline B2A2-8 & office 10 & 35 & 135 & 3.9 & 29.19 & 0.834 & 3.55 & 0.76759 \\
\hline B2A2-9 & office 11 & 46 & 160 & 3.5 & 32.21 & 0.700 & 3.55 & 0.71466 \\
\hline B2A2-10 & archive & 16 & 68 & 4.3 & 25.91 & 1.619 & 3.55 & 1.35265 \\
\hline
\end{tabular}




\subsubsection{Integration of the Box-Model in a BIM Environment}

To set up an automatic calculation within the BIM authoring Autodesk Revit, a schedule (Figure 11) was set up of all the BIM elements in the Rooms category with a succession of "calculated parameters" also called "calculated values".

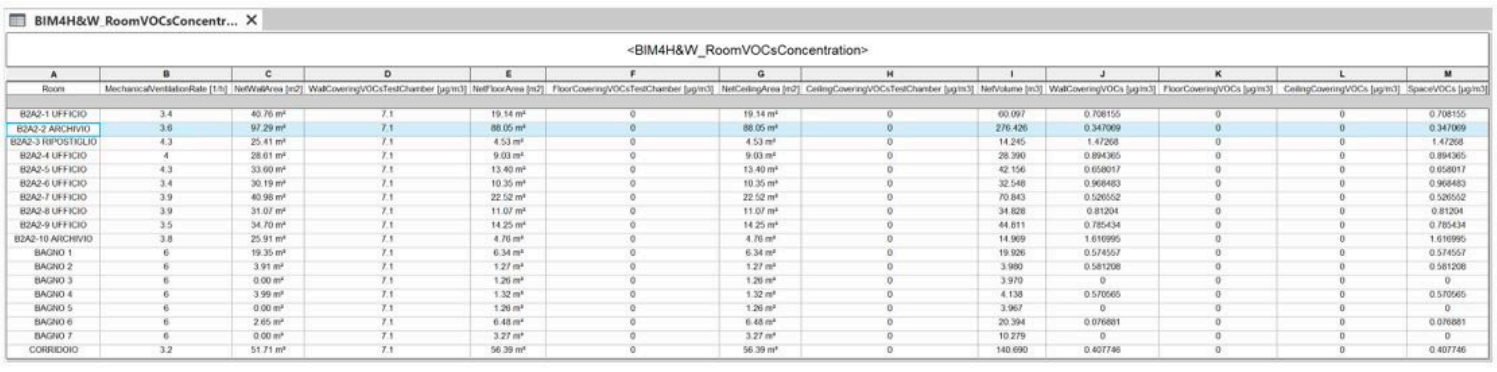

BIM4H\&W RoomVOCsConcentr... $\times$

\begin{tabular}{|c|c|c|c|c|c|c|}
\hline \multicolumn{7}{|c|}{ <BIM4H\&W_RoomVOCsConcentration> } \\
\hline A & B & c & D & E & $\mathbf{F}$ & $\mathbf{G}$ \\
\hline Room & NetVolume [m3] & MechanicalVentilationRate $[1 / \mathrm{h}]$ & NetWallArea [m2] & WallCoveringVOCsTestChamber $[\mathrm{\mu g} / \mathrm{m} 3]$ & WallCoveringVOCs $[\mu \mathrm{g} / \mathrm{m} 3] \mathrm{s}$ & SpaceVOCs $[\mu \mathrm{g} / \mathrm{m} 3]$ \\
\hline B2A2-1 UFFICIO & 60.097 & 3.4 & 40.76 & 7.1 & 0.708155 & 0.708155 \\
\hline B2A2-2 ARCHIVIO & 276.426 & 3.6 & 97.29 & 7.1 & 0.347069 & 0.347069 \\
\hline B2A2-3 RIPOSTIGLIO & 14.245 & 4.3 & 25.41 & 7.1 & 1.47268 & 1.47268 \\
\hline B2A2-4 UFFICIO & 28.390 & 4 & 28.61 & 7.1 & 0.894365 & 0.894365 \\
\hline B2A2-5 UFFICIO & 42.156 & 4.3 & 33.60 & 7.1 & 0.658017 & 0.658017 \\
\hline B2A2-6 UFFICIO & 32.548 & 3.4 & 30.19 & 7.1 & 0.968483 & 0.968483 \\
\hline B2A2-7 UFFICIO & 70.843 & 3.9 & 40.98 & 7.1 & 0.526552 & 0.526552 \\
\hline B2A2-8 UFFICIO & 34.828 & 3.9 & 31.07 & 7.1 & 0.81204 & 0.81204 \\
\hline B2A2-9 UFFICIO & 44.811 & 3.5 & 34.70 & 7.1 & 0.785434 & 0.785434 \\
\hline B2A2-10 ARCHIVIO & 14.969 & 3.8 & 25.91 & 7.1 & 1.616995 & 1.616995 \\
\hline BAGNO 1 & 19.926 & 6 & 19.35 & 7.1 & 0.574557 & 0.574557 \\
\hline BAGNO 2 & 3.980 & 6 & 3.91 & 7.1 & 0.581208 & 0.581208 \\
\hline BAGNO 3 & 3.970 & 6 & 0.00 & 7.1 & 0 & 0 \\
\hline BAGNO 4 & 4.138 & 6 & 3.99 & 7.1 & 0.570565 & 0.570565 \\
\hline BAGNO 5 & 3.967 & 6 & 0.00 & 7.1 & 0 & 0 \\
\hline BAGNO 6 & 20.394 & 6 & 2.65 & 7.1 & 0.076881 & 0.076881 \\
\hline BAGNO 7 & 10.279 & 6 & 0.00 & 7.1 & 0 & 0 \\
\hline CORRIDOIO & 140.690 & 3.2 & 51.71 & 7.1 & 0.407746 & 0.407746 \\
\hline
\end{tabular}

Figure 11. Schedule within Autodesk Revit that allows the application of the box-model to calculate the concentration of VOCs present in a room due to the presence of emissive finishing materials. Above the complete schedule with walls, floors, ceilings, and rooms VOCs parameters, below the part with only the wall and room VOCs parameters.

First, it was necessary to fill the parameters that must contain project values:

- MechanicalVentilationRate: The number of air changes required in the mechanical ventilation design.

- WallConveringVOCsTestChamber, FloorConveringVOCsTestChamber, Ceiling-ConveringVOCs TestChamber: The concentration value, $C_{C H}\left[\mu \mathrm{g} / \mathrm{m}^{3}\right]$, in the air inside the "test chamber", which can be found in the technical data sheets of the material.

In the case study, the only finish that has an emissive material is that of the walls, while floors and false ceilings have no emissive materials and their $C_{C H}\left[\mu \mathrm{g} / \mathrm{m}^{3}\right]$ is zero.

Subsequently, the net finishing area of the walls of all the rooms was entered in the "IfcQtyNetWallArea" parameter using the free add-in "Roombook Areabook Buildingbook for Revit", which allows us to extrapolate the side surfaces of the rooms by subtracting the area of doors and windows.

Finally, the calculated parameters are added using the Equations (10) explained in the method section. Figure 12 shows the syntax used for the formulation must be compiled within the calculated value "WallCoveringVOCs. The suffix "_C" indicates that they are calculated values. 


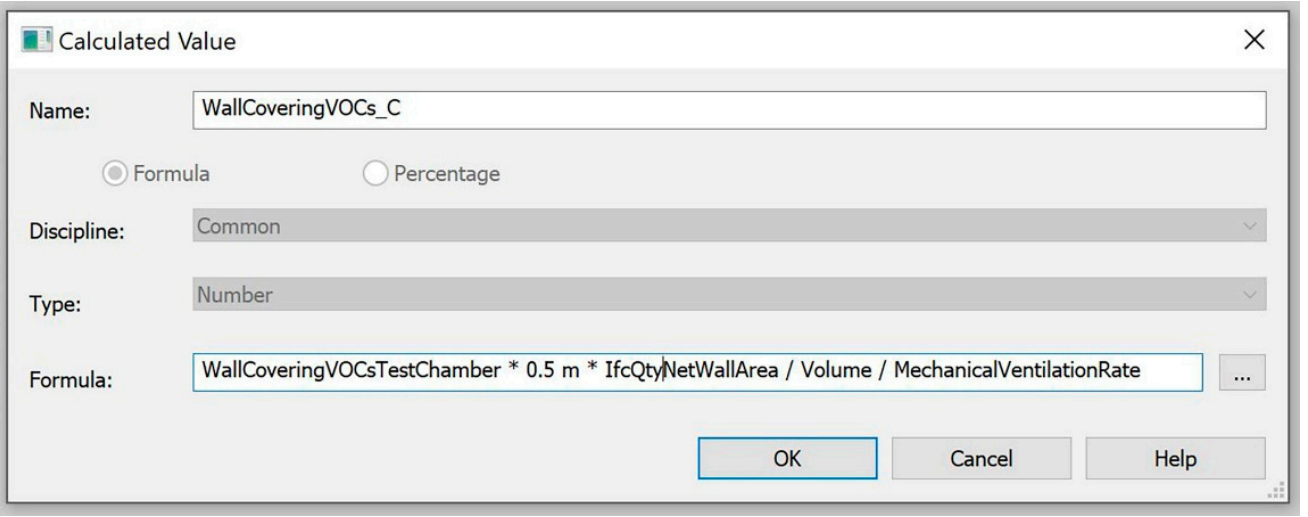

Figure 12. Setting for the calculated parameter "WallCoveringVOCs_C" in a Revit schedule.

We are forced to use calculated parameters because in Autodesk Revit it is not possible to create a calculated parameter starting from a shared parameter.

We can then copy the values of the calculated parameters within the respective shared parameters and the BuiltIn Revit parameters in the corresponding shared parameters with the IFC standard nomenclature (13):

$$
\begin{gathered}
\text { WallCoveringVOCs_C }=\text { WallCoveringVOCs } \\
\text { FloorCoveringVOCs_C }=\text { FloorCoveringVOCs } \\
\text { CeilingCoveringVOCs_C }=\text { CeilingCoveringVOCs } \\
\text { SpaceVOCs_C }=\text { SpaceVOCs } \\
\text { Volume }=I f c Q t y N e t V o l u m e
\end{gathered}
$$

The BuiltIn Revit "Area" parameter is automatically written to the standard of "NetFloorArea" parameter. This last activity of copy/paste values has the sole purpose of being able to export an IFC file from Revit containing the parameters of the BIMH\&W workflow and consistent with the IFC4.1 international schema.

To copy the values from one parameter to another, a script was developed in Dynamo (Figure 13) to automate the process and avoid possible user distraction errors. The IFC export settings from Revit that guarantee the correct writing of the parameters are the following: IFC4 Reference View; Export IFC common property sets; Export base quantities. Table 8 shows the calculated values for the rooms of the BIM model developed in Autodesk Revit.

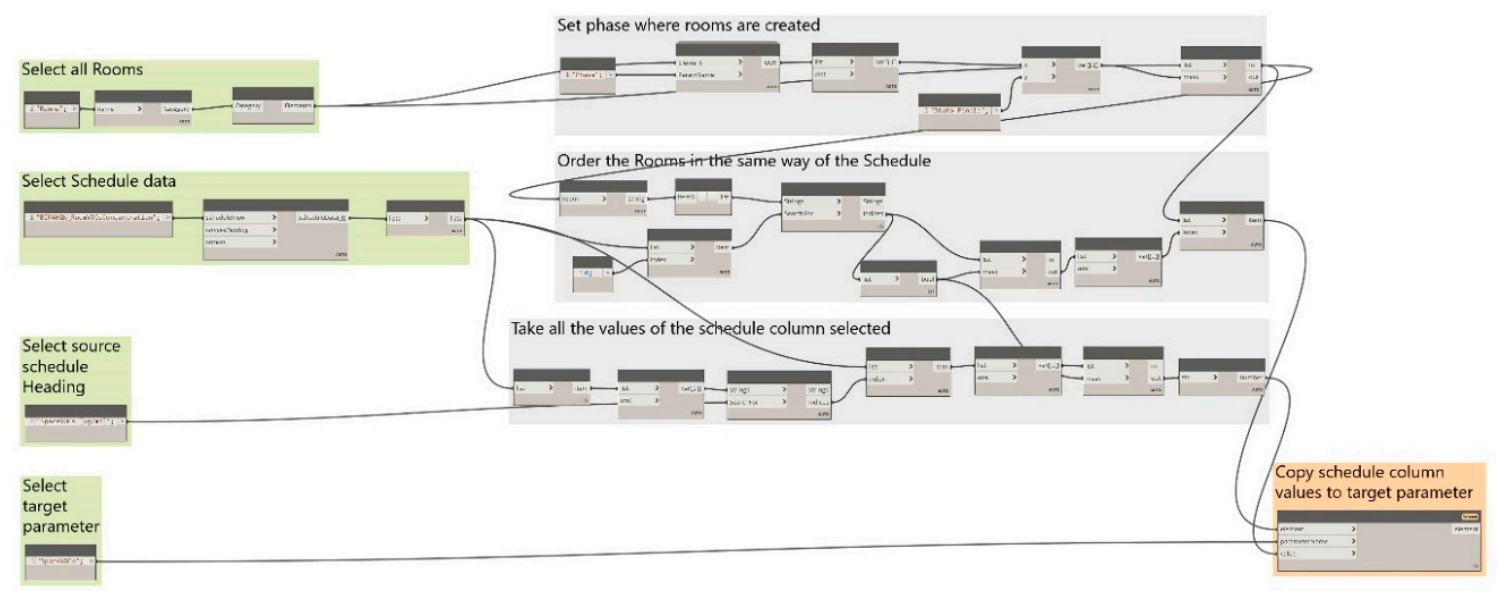

Figure 13. Dynamo script to copy the calculated values "SpaceVOCs_C" present in a schedule in the corresponding shared parameters "SpaceVOCs" assigned to the project rooms. 
Table 8. VOC concentrations calculated with the box-model implemented within the BIM authoring Autodesk Revit.

\begin{tabular}{|c|c|c|c|c|c|c|c|}
\hline \multicolumn{2}{|c|}{ Room } & \multirow{2}{*}{$\begin{array}{c}\begin{array}{c}\text { Net } \\
\text { Volume }\end{array} \\
\mathbf{m}^{3}\end{array}$} & \multirow{2}{*}{$\begin{array}{c}\text { Mechanical } \\
\text { Ventilation } \\
\text { Rate }\end{array}$} & \multirow{2}{*}{$\begin{array}{c}\text { NetWallArea } \\
\mathrm{m}^{2}\end{array}$} & \multirow{2}{*}{$\begin{array}{c}\begin{array}{c}\text { WallCovering } \\
\text { VOCs } \\
\text { TestChamber }\end{array} \\
\mu \mathrm{g} / \mathrm{m}^{3}\end{array}$} & \multirow{2}{*}{$\begin{array}{c}\text { WallCovering } \\
\text { VOCs }\end{array}$} & \multirow{2}{*}{$\begin{array}{c}\text { SpaceVOCs } \\
\mu \mathrm{g} / \mathrm{m}^{3}\end{array}$} \\
\hline & & & & & & & \\
\hline B2A2-1 & office 3 & 60.097 & 3.4 & 40.76 & 7.1 & 0.708155 & 0.708155 \\
\hline B2A2-2 & meeting & 276.426 & 3.6 & 97.29 & 7.1 & 0.347069 & 0.347069 \\
\hline B2A2-3 & closet & 14.245 & 4.3 & 25.41 & 7.1 & 1.47268 & 1.47268 \\
\hline B2A2-4 & office 5 & 28.390 & 4 & 28.61 & 7.1 & 0.894365 & 0.894365 \\
\hline B2A2-5 & office 6 & 42.156 & 4.3 & 33.60 & 7.1 & 0.658017 & 0.658017 \\
\hline B2A2-6 & office 7 & 32.548 & 3.4 & 30.19 & 7.1 & 0.968483 & 0.968483 \\
\hline B2A2-7 & office 8-9 & 70.843 & 3.9 & 40.98 & 7.1 & 0.526552 & 0.526552 \\
\hline B2A2-8 & office 10 & 34.828 & 3.9 & 31.07 & 7.1 & 0.81204 & 0.81204 \\
\hline B2A2-9 & office 11 & 44.811 & 3.5 & 34.70 & 7.1 & 0.785434 & 0.785434 \\
\hline B2A2-10 & archive & 14.969 & 3.8 & 25.91 & 7.1 & 1.616995 & 1.616995 \\
\hline corridor & corridor & 140.690 & 3.2 & 51.71 & 7.1 & 0.407746 & 0.407746 \\
\hline
\end{tabular}

\subsubsection{Comparison between Box-Model and Its Application in BIM}

The graph in Figure 14 compares the concentration values obtained using box-model and the BIM process. The values are evidently in excellent agreement as proof of the correct implementation of box-model in the BIM process. It is possible to notice that the concentration values automatically calculated within the BIM are slightly higher. This depends on the ability of this modelling to consider in a more detailed and precise way the constructive characteristics of the environments, such as the surfaces, which contribute to determining the emissions and therefore the concentration in the environments themselves.

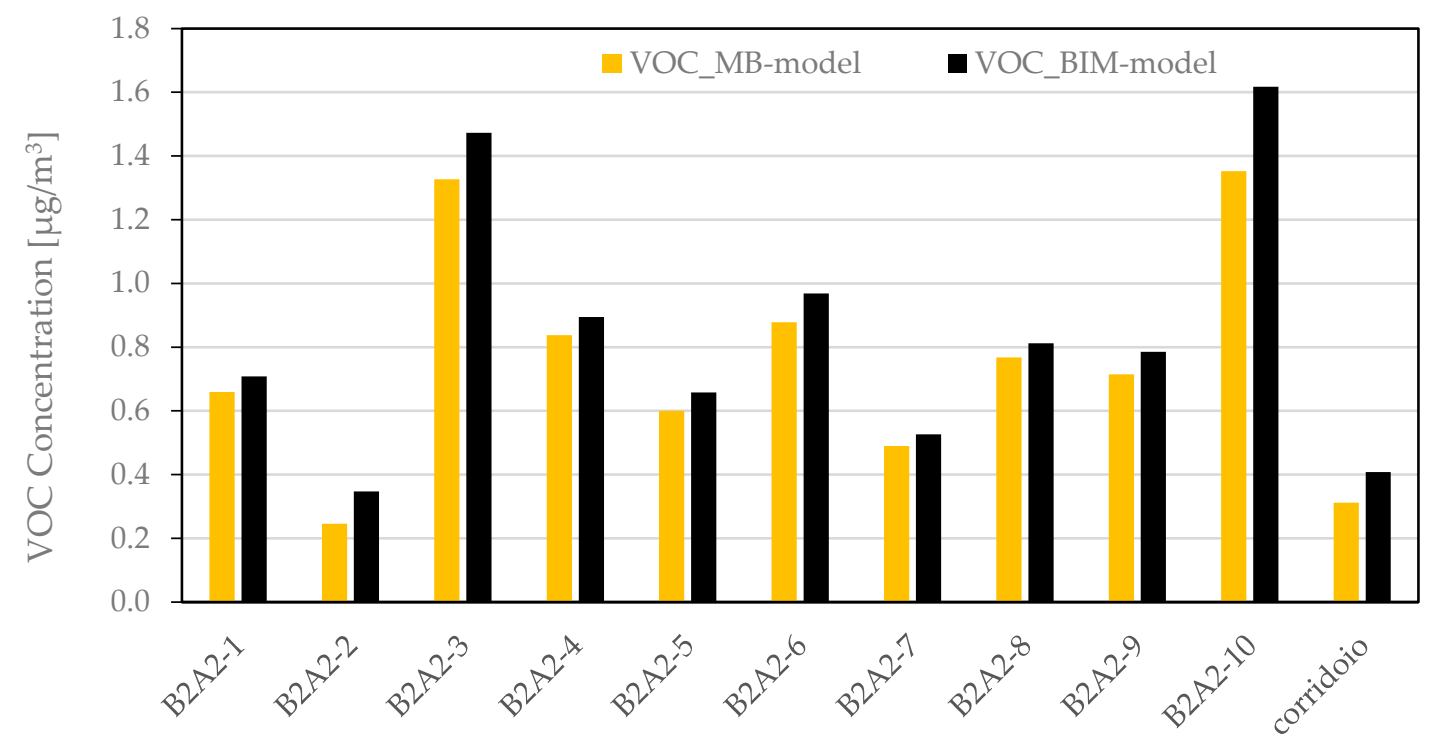

Figure 14. VOC concentrations simulated with the box-model using mass balance approach (MB-model-in yellow) and by implementing it in the BIM process (BIM-model-in black).

\subsection{Model Checker in the BIM Process to Verify Indoor VOC Concentration Related to IAGVs}

Similarly to the check procedure implemented for the parameters assigned to the materials of the BIM model, the correct insertion of the parameters assigned to the rooms/spaces of the BIM model is carried out.

The verification that the parameter SpaceVOCs is $<50 \mu \mathrm{g} / \mathrm{m}^{3}$ is implemented, as shown in Figure 15, through the code of a check rule with "Autodesk Model Checker", similarly to the previous cases (see Section 3.2.1). 


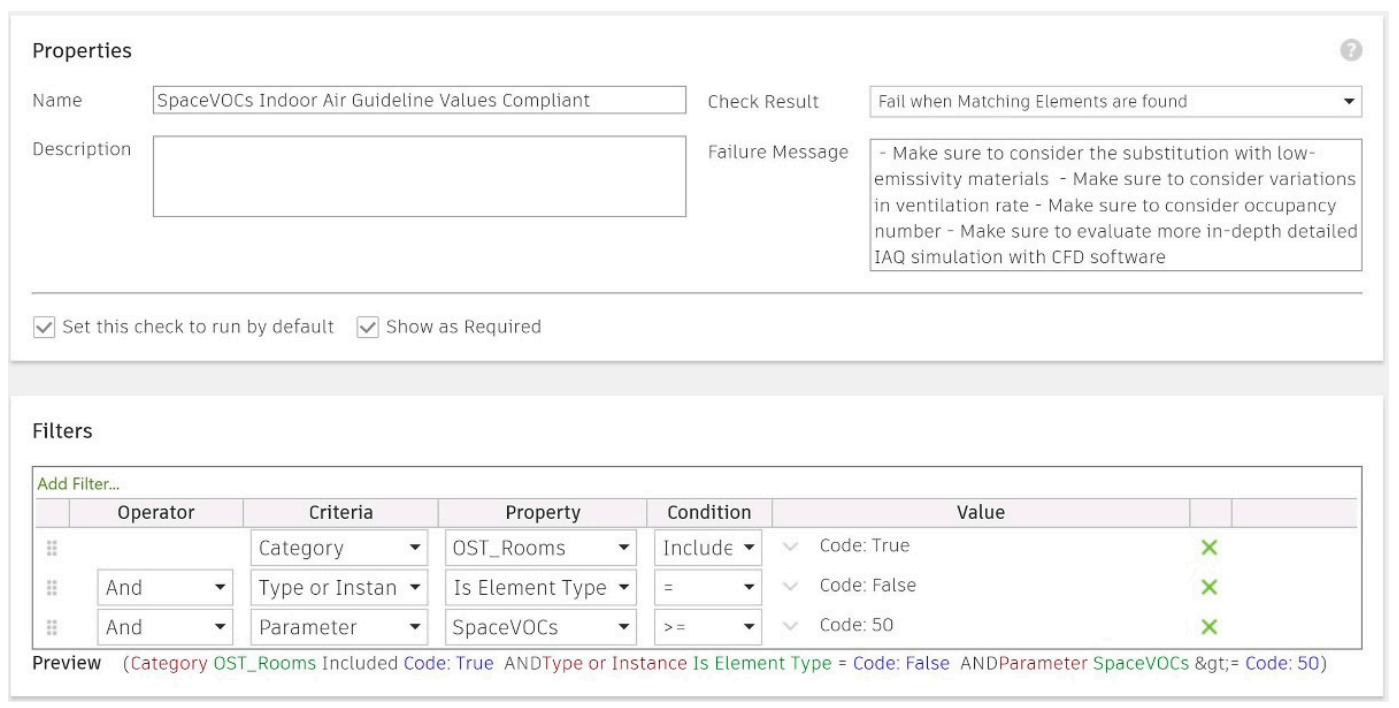

Figure 15. CheckSet to check the value of the SpaceVOCs parameter.

Figure 16 (right) shows the "Autodesk Model Checker" screen if the value of the SpaceVOCs parameter exceeds the pre-established threshold. In this case, more in-depth checks are suggested to the designer and possible alternative solutions proposed are:

- $\quad$ Make sure to consider the substitution with low-emissivity materials.

- $\quad$ Make sure to consider variations in ventilation rate.

- Make sure to consider occupancy number.

- $\quad$ Make sure to evaluate more in-depth detailed IAQ simulation with CFD software.

(a)

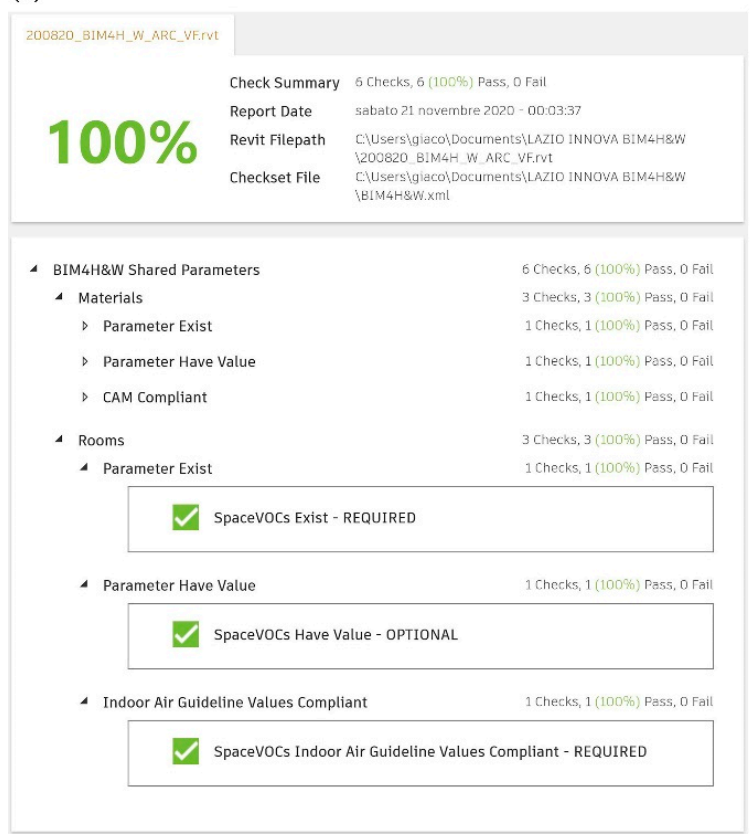

(b)

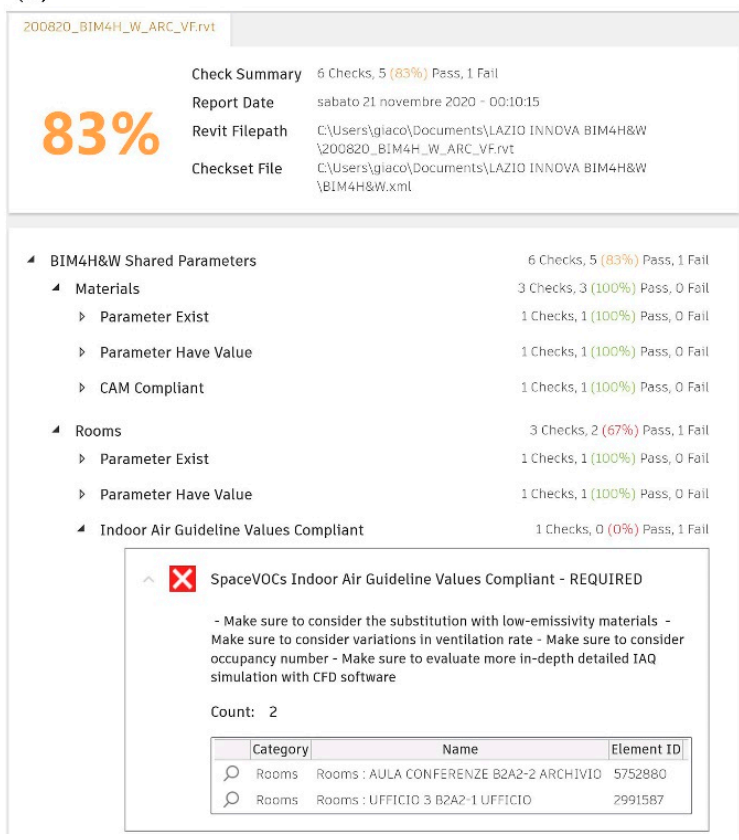

Figure 16. Report implemented on the BIM model in which all the rooms have VOC emission values below the identified limit (a); or in which two rooms have VOC emission values higher than the identified limit $(\mathbf{b})$. 
The final representation (Figure 17) shows two plants in which a colour scheme is set on the rooms such that those with the value of the "SpaceVOCs" parameter lower than the threshold value are coloured green, while the rooms with a "SpaceVOCs" value greater than the threshold value are coloured red. In the example, the rooms coloured in red are set in a forced manner; they do not reflect the true values of the case study. The colour scheme developed in Revit is shown in Figure 18.

(a)

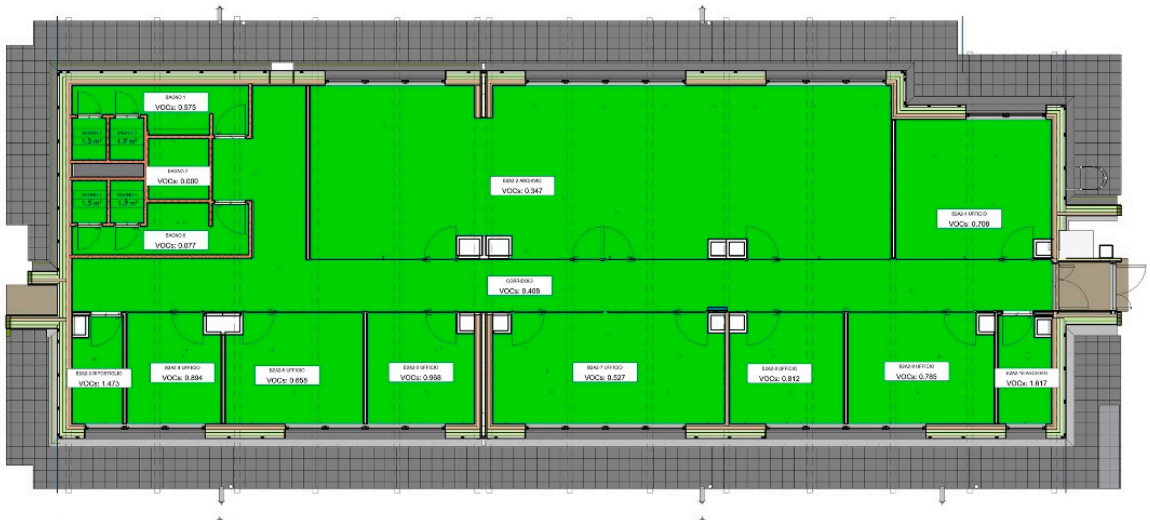

(b)

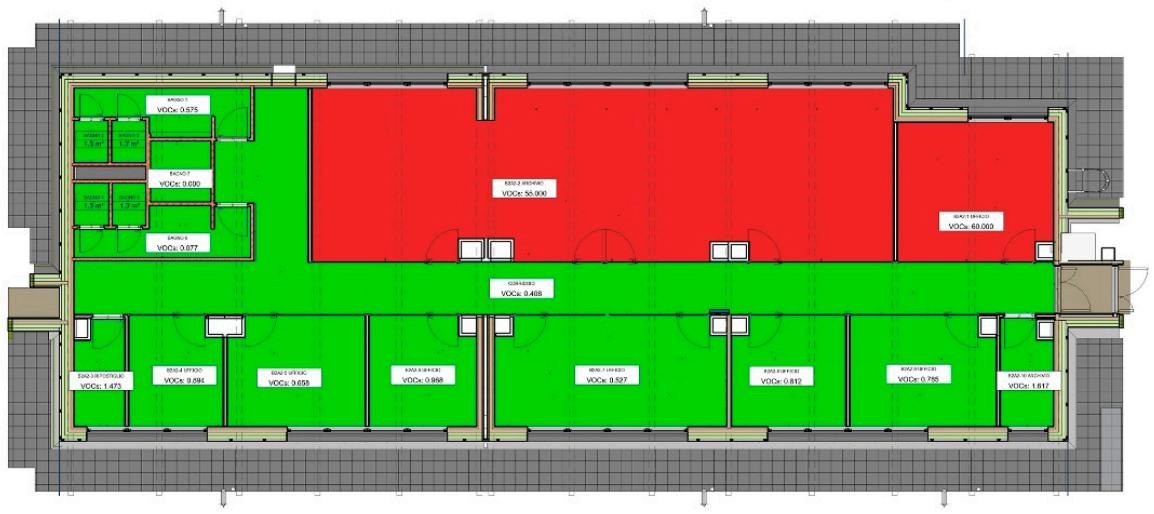

Figure 17. (a) Colour scheme set on the rooms of the "SpaceVOCs" parameter in which all the rooms are green because they have VOC emission values below the identified limit; or (b) in which two rooms are red because they have VOC emission values above the identified limit.

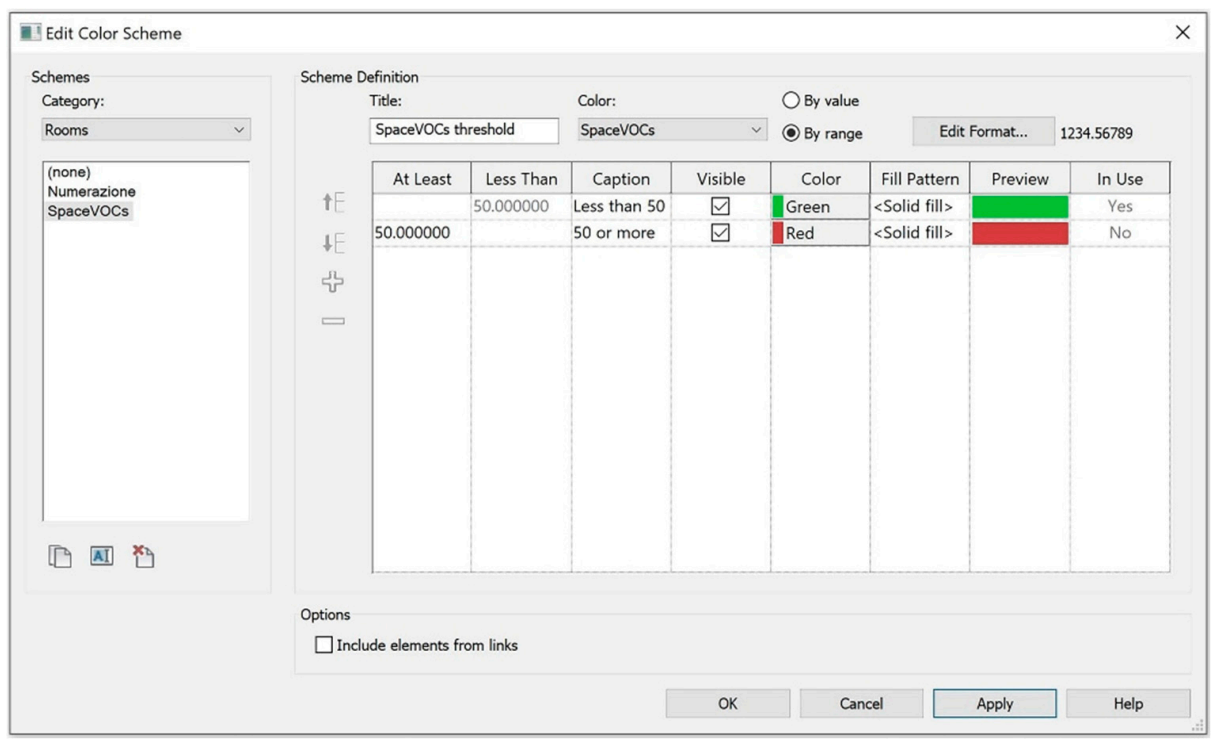

Figure 18. Colour Scheme for the visualisation of the green and red coloured rooms, respectively, if they are lower or higher than the SpaceVOCs threshold value. 


\section{Discussion}

\subsection{Use of Digital Design and BIM Process toward Healthy Buildings}

In design practice, the process can now systematically make use of digital tools, such as BIM, for the analysis of environmental performance. Information modelling is an integral part of the project, characterised by an iterative process, whereby a design choice is followed by a simulation and performance evaluation to quantitatively measure its effectiveness (Figure 19).

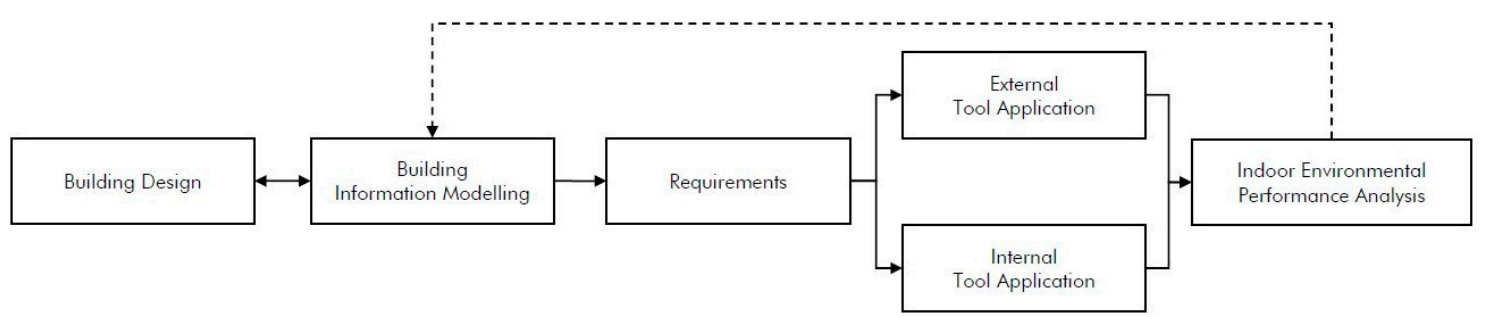

Figure 19. The BIM Workflow for Indoor Environmental Performance Analysis. Based on the presented BIM workflow on the Technical report "BUILDING INFORMATION MODELING (BIM) for Indoor Environmental Performance Analysis" by University of Aarhus [31].

In this context, the term "Green BIM" is increasingly widespread, meaning the application of the BIM process to the assessment of energy performance and sustainability of buildings. The ability of BIM to manage information relating to the various disciplines of the project can also speed up and optimise the verification of protocols for assessing sustainability. BIM process could respond to the need to automatically manage the check of the satisfaction of the credit for the GBRS (Green Buildings Rating Systems). These have become more complex due to a differentiated demand, which has led the responsible institutions (i.e., LEED, BREEAM) to develop diversified versions for the different types of interventions/buildings (new constructions, and renovations, for residential or office use). This complexity, therefore, requires tools that can automatically manage the verification of the characteristic requirements of each type of intervention, and BIM can respond to this need.

However, the drafting of protocols for sustainability is an activity that is integrated into the design phase but is currently difficult to automate, although the scientific community is moving to optimise some credit verification processes with BIM-based methodologies [39].

The field of investigation of energy performance is certainly the most advanced, so even the BIM application to protocols for sustainability has focused almost exclusively on the development of tools and plug-ins applied to the study of energy issues [53], while the topics relating to the aspects of health and well-being appear still little investigated. Among the most interesting applications currently in use are to be mentioned: Autodesk Green Building Studio; IES VE-Toolkit for LEED and BREEAM certification, and Autodesk Insight for Revit.

Cheng and Nguyen identify two main problems regarding the integration between BIM software functions and certification processes [54]:

- $\quad$ BIM is above all enabled for the analysis of building performance and not applicable to many of the other categories that contribute to the output of rating systems;

- Manual operations are still required to switch from one application to another with file export and import.

However, BIM software is databases from which it is possible to extract information, useful in association with other applications to calculate the credits of many categories of rating systems or to communicate with applications that have difficulty exchanging open file formats to date. At the basis of these exchanges are the two mainly used open formats, the IFC, already discussed in the previous 
sections, and the gbXml (green building XML). The main limitations highlighted in the processes present in the literature are related to the definition of all attributes, of which the new ones conform to the current IFC scheme, to satisfy the criteria calculation procedures [55]. Furthermore, not all the attributes necessary for the calculation of the score are included in the list of IFC properties, so some of these (in particular the output data) must be created.

Precisely in light of these reflections, the presented contribution is concentrated on Indoor Environment Quality, and in particular on IAQ, directing research on integration with BIM systems, as directly as possible within the selected Authoring Software, avoiding export and import steps on one hand, while proposing integration of the openBIM (IFC) format on the other.

Although the workflow presented is not aimed directly at the management of GBRS credits, this constitutes the first step of an in-depth study of a research field still under development and it could allow to fulfil the credits related to the issue of the materials of some sustainability protocols already in the presented stage, as well as demonstrating the CAM satisfaction for Italian legislation and moving towards the purpose of the salutogenic aim. Given the discussion on display, the strategy in which the developed tool is adopted is broader and aims to increase the awareness of designers on the issues of health and wellness needs. The main purposes of the methodology presented are the verification of the emission requirements of the individual materials and the control of the concentrations of pollutants in an indoor environment, two concepts linked together, even if different.

\subsection{Criticalities in the Open BIM Process and Definition of "Shared Parameters"}

To be as consistent as possible with the procedure recommended by Autodesk for inserting standard IFC parameters, the "Shared parameters" present in the official txt file "IFC Shared Parameters-Revit" were analysed, and three critical issues were found:

1. The "MechanicalVentilationRate" parameter is present but it is set as "Integer" data type, while we need to be able to enter decimal numbers as required by the IFC diagram in the "Pset_SpaceThermalRequirements";

2. The "NetWallArea", "NetCeilingArea" and "NetVolume" parameters are not present, but in their place, there are the "IfcQtyNetWallArea", "IfcQtyNetCeilingArea" and "IfcQtyNetVolume" parameters, because in Autodesk Revit, only for the IfcSpace class, it is possible to overwrite the QuantitySet parameters "Qto_SpaceBaseQuantities" by inserting the suffix "IfcQty" to the name of the IFC schema parameter. If we export a Revit model in IFC format, the standard parameters "NetWallArea", "NetCeilingArea" and "NetVolume" are not written automatically (Figure 20);

3. The "NetFloorArea" and "IfcQtyNetFloorArea" parameters are not present even if provided for in the IFC 4.1 diagram within the "Qto_SpaceBaseQuantities". If we export a Revit model in IFC format, the standard parameter "NetFloorArea" is automatically written in the "Qto_SpaceBaseQuantities" (Figure 20) with the same value that is present in Autodesk Revit in the "Area" parameter of the "Rooms".

The critical issues exposed represent a limitation to the openBIM process through an open format such as IFC, forcing the operator to set a different path depending on the chosen BIM Authoring software. In the case described, the criticality was overcome as described in the relevant section of the results (see Section 3.1). 


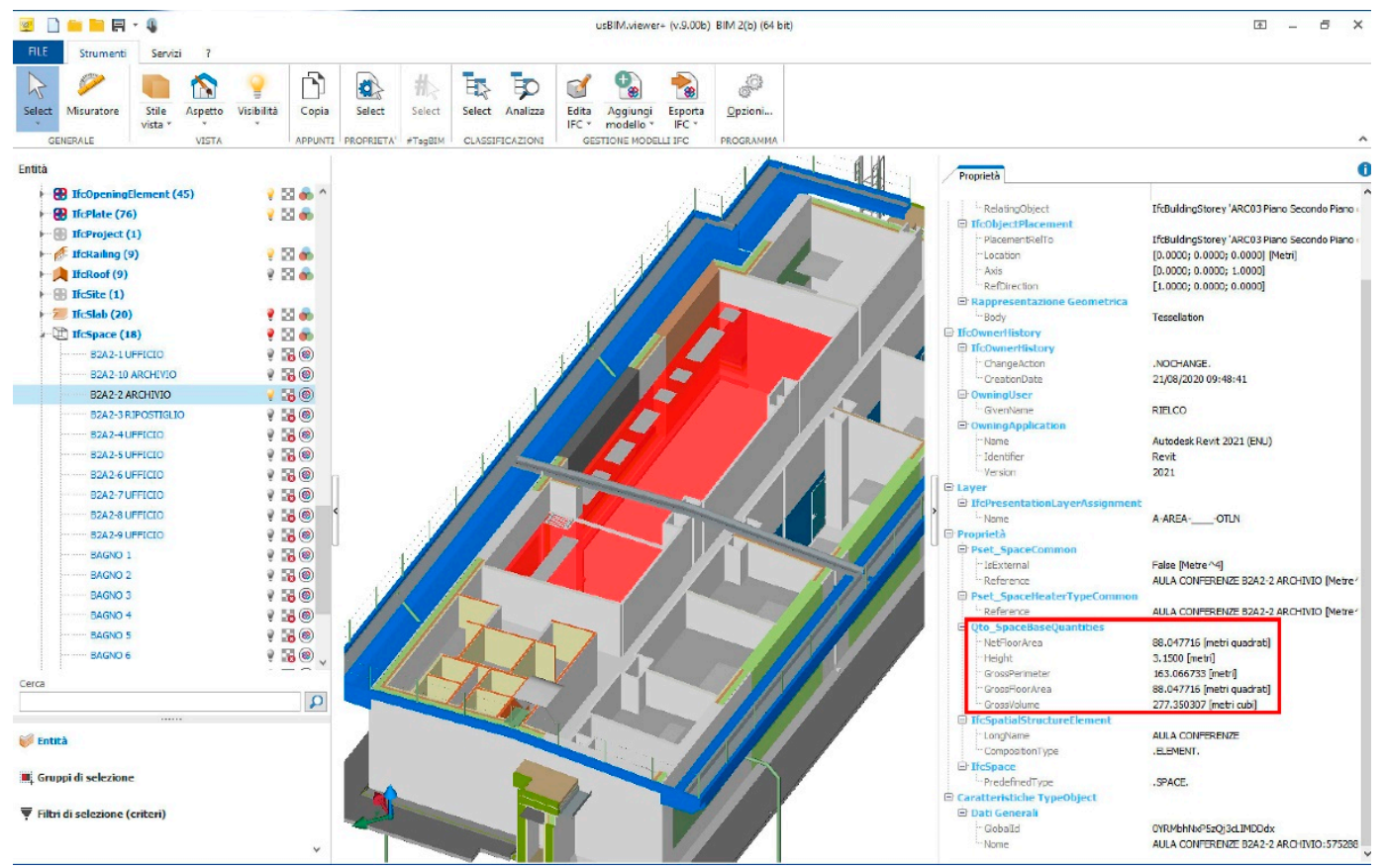

Figure 20. Analysis of the parameters of an IfcSpace present in the QuantitySet "Qto_SpaceBaseQuantities" of an IFC model exported from Revit without the inclusion of any "shared parameters". IFC viewer used: ACCA usBIM.viewer+ [56].

\subsection{Technical Requirements of Building Components for IAQ Control}

The results of the analyses showed that the satisfaction of the emission threshold values (i.e., for the LEED and BREEAM protocols) and the regulatory limits (CAM), do not have a direct correspondence with high indoor air quality. The upper limit imposed by the CAM $\left(1500 \mu \mathrm{g} / \mathrm{m}^{3}\right)$ must be contextualised concerning the actual air changes of the environment being analysed. Considering a minimum turnover of 0.5 volumes/hour, as described by the regulations for the evaluation of individual materials, the correspondent indoor concentration value obtained is far above the IAGVs elaborated in the scientific literature.

A fundamental role in the evaluation of IAQ is therefore linked to air changes and the design of the HVAC system. The greater the ventilation rate the system is designed with, the greater the dilution of the substances present in the air and, therefore, the lowering of their concentration. The considerations set out here have taken into account the minimum air change (a value of 0.5 volumes/hour) for two main reasons:

- It is not always possible to know the air changes of the HVAC system, in the early stages of the development of the architectural project, or it is not certain that there are air changes higher than the minimum in the absence in mechanised ventilation (i.e., in residential buildings);

- In the case of the HVAC system with ventilation rates higher than 0.5 , a malfunction could occur, which would lead to an accumulation of VOCs in an indoor environment.

The method presented here is intended to be a first verification tool for the designer on the IAQ performance of the building organism. This tool focuses on the performance of the building box, precisely to allow the evaluation of design choices, and the proposed threshold value is precautionary because the contributions of users, furnishings, and cleaning systems must be considered in the real situation, in addition to the ones of the construction elements. All these other contributions are more complex simulation in the early stages of the project.

A critical issue that emerged during the development of the research project relates to the topic knowledge by the technicians and manufacturers of building materials. Although it is true that to date 
the majority of construction products are certified and report emission data, these data still appear to be incomplete or not correctly disseminated.

The issues can be summarised in the following list:

- Materials with technical data sheets containing incomplete emission data: Not always all the main indoor pollutants are present (i.e., Formaldehyde, VOC, Benzene);

- Unclear understanding of the VOC emission data: When the data are present, it is often not specified with which procedures and tests the value was obtained, how many days after application it refers to, and whether the declared data refer to the VOCs contained in internal material or those emitted.

In most cases, when present, the VOC emission data referred to the TVOCs and not to a specification, at least to the main ones. However, it should be noted that there were also manufacturers who provided complete data of certifications and indications on the methods of testing the emissivity of materials, and which allowed the analyses carried out.

These considerations have directed the project to focus on the TVOC data, which therefore appears to be the one actually easier to find even for architectural designers.

It is certainly necessary to work for greater awareness of the IAQ theme and an increase in the technical knowledge of both the designers, who must request the information, and the manufacturers who must provide it, to make the design towards Healthy Buildings and the simulation of significative performances more effective.

\subsection{Limitations and Future Research Directions}

In the present work, the methodology described for the estimation of VOC concentration in indoor environments, box-model, and its implementation in the BIM process, has been applied considering simplifying conditions. We decided to simulate the emission of VOCs in the rooms as coming from a single type of material: the internal finishing paint applied to the walls. This choice, while offering a limited estimate of the real concentration in the environments, allowed to highlight the contribution from the materials in the indoor concentrations' assessment. The choice is also simplifying from the point of view of the actual composition of the materials present in the rooms. The material charged with the emission of VOC is in fact with this hypothesis considered as composed solely of the finishing layer, thus not considering the presence of the underlying layers.

We decided to make this simplification since it is known from the literature that the emissions from multilayer materials are comparable with those of the outermost top-layer material [57]. At the same time, because over the years the phenomena of diffusion within multilayer materials have been extensively investigated [58], the integration of this modelling into the BIM process represents a field of sure interest and possible future development.

The choice of the TVOC parameter only has been discussed in Section 4.1., but the elaborated workflow was designed to be implementable concerning other indoor pollutants, and in the test phase, the shared parameters relating to Formaldehyde, Benzene, and $\mathrm{CO}_{2}$, have already been evaluated and entered.

A final aspect to be addressed in the discussion is relating to the integration between BIM and CFD simulation. To date, file exchange is still difficult and not direct, and among the many simulation software (i.e., CONTAM, COMIS, IAQx, ANSYS, and Autocad CFD) few manage the IFC format [32]. Among these, the latter is the only one that allows exchange with the files processed within the BIM Authoring Revit, being from the same software house.

The input data required for IAQ modelling can be classified into:

- Boundary conditions necessary for the fluid-dynamics: Indoor/outdoor momentum exchanges to the indoor domain, geometric characteristics of the indoor domain, thermal forcing (external and internal temperatures); 
- Information to simulate transport and diffusion of contaminants: Initial conditions (source position, introduced flow rates) and chemical characteristics of the contaminants.

The IAQ assessment requires information on indoor pollutants as input data and many of these data depend on the activities carried out in the building during the occupation, which are difficult to acquire from the BIM model. However, IAQ is very complex due to a large number of boundary conditions necessary for the simulation, that results too detailed to be captured by an IFC model and linked to a specific dynamic calculation tool. Research efforts in this direction are needed, as IAQ should not be neglected and applied only during the "use phase" of buildings. The part of the input data required for the IAQ assessment during the early design stages such as geometric details, intended occupation, HVAC details, and technical specifications of the building materials can be obtained by querying the BIM model [32].

Future research may envisage the possibility of linking BIM design variables and computational data needed to use CFDs and their integration. For now, the large amounts of input data required for CFD simulations still make the software more applicable in the later stages of the detailed design phase. However, the time and resources required will be reduced with the advancement of more powerful hardware and hopefully future BIM implementations.

\section{Conclusions}

The concept of "Healthy Building" thus asserts itself as a new paradigm of environmental sustainability. The studies cited in the contribution highlight the centrality of the topic for the performance analysis of the built environment, specifically concerning the construction practice that in recent decades have focused on energy performance to the detriment of users' health. The profound qualitative changes of indoor air and the progressive increase in the absolute number of pollutants, combined with the scientific awareness of the health impacts deriving from spending more than $90 \%$ of one's time inside confined spaces, has therefore increased the attention to the needs of well-being, hygiene, and health of the users. This scientific attention has produced studies and analyses aimed at an evidence-based investigation for deepening the performance aspects of the building system, demonstrating the importance of the interdisciplinary nature of architectural engineering.

Although from a theoretical point of view, what is reported highlights the need to deepen the research topic, from an operational point of view the question is certainly more complex. Associating a performance value with each element of the environmental and technological system through the compilation of data fields or automated calculation procedures, exploiting the potential of BIM processes, is a new challenge.

The limitation of the topic results, on the one hand, the definition of performance specifications, based not only on the regulatory environment as in actual practice but on an evidenced-based approach; and on the other hand the possibility of attributing and extrapolating evaluations and requirements from the models in a quantitative format.

The contribution demonstrates how it is possible to integrate performance-based analysis into BIM processes aimed at assessing IAQ, for Healthy Buildings design, operating through a multidisciplinary approach and numerical simulations outside of the consolidated information modelling in the construction sector. The results of the contribution show a good fit between the numerical model and the implementation in BIM, providing the designer with a quick control tool for IAQ in the various phases of the architectural project. The design choices concerning mechanical ventilation systems and building materials are certainly fundamental and must be analysed in the whole process of design and construction of the building.

The research presented here is a first development, currently focused on TVOC, but implementable concerning other aspects of IAQ, a direction necessary for the effectiveness of performance building-based design for health and wellness issues. Further insights and analyses will allow to better set the workflow and the tool, testing it on a higher number of case studies. 
Author Contributions: Conceptualisation, A.D. and E.C.; methodology, A.D.; software, G.B.; BIM model analysis A.D. and G.B., numerical model analysis A.P.; investigation, A.D., G.B. and A.P.; architectural engineering A.D. and E.C.; writing —original draft preparation, A.D.; writing—review and editing, A.D., G.B., A.P., E.C.; visualisation, A.D., G.B.; supervision, E.C.; funding acquisition, E.C. All authors have read and agreed to the published version of the manuscript.

Funding: The research project is funded by the Lazio Region (Det. N. G12783 of 20/09/2017) POR FESR LAZIO 2014/2020-Integrated projects-Public notice 6 "Creativity 2020" CUP Code B16C18001020007 n. prot. A0128-2017-17209. The research, entitled "BIM4H\&W: BIM for Health and Wellbeing" is developed in partnership of effective collaboration between RI.EL.CO IMPIANTI S.R.L. and the University of Rome "Sapienza", CRITEVAT-Reatine Research Center in Engineering for the Protection and Enhancement of the Environment.

Acknowledgments: Thanks to RIELCO IMPIANTI S.R.L. for the support during the development of the research and the material provided on the case study of the New expansion of CNR in Pisa, Italy. We also thank all the technicians of the company who contributed to the achievement of the research objectives.

Conflicts of Interest: The authors declare no conflict of interest.

\section{References}

1. Zanchetta, C.; Croatto, G.; Paparella, R.; Turrini, U. Performance based building design to ensure building quality: From standardization to LEAN construction. TECHNE 2014, 8, 62-69. [CrossRef]

2. Sanguinetti, P. BIM in academia: Shifting our attention from product to process. In Joining Languages, Cultures and Visions: CAADFutures 2009; Tidafi, T., Dorta, T., Eds.; PU Montreal: Montreal, QC, Canada, 2009; pp. 395-409.

3. Penttilä, H. Describing the Changes in Architectural Information Technology to Understand Design Complexity and Free-form Architectural Expression. J. Inf. Technol. Constr. Itcon 2006, 11, 395-408.

4. Howard, R.; Björk, B.C. Building information modelling-Experts' views on standardisation and industry deployment. Adv. Eng. Inform. 2008, 22, 271-280. [CrossRef]

5. Eastman, C.M. The Representation of Design Problems and Maintenance of Their Structure. In Artificial Intelligence and Pattern Recognition in Computer Aided Design; Latombe, J.C., Ed.; North-Holland Press: New York, NY, USA, 1979.

6. World Health Organization (WHO). Health as the Pulse of the New Urban Agenda: United Nations conference on Housing and Sustainable Urban Development; WHO Library Cataloguing-in-Publication Data: Quito, Ecuador, 2016.

7. Capolongo, S.; Rebecchi, A.; Dettori, M.; Appolloni, L.; Azara, A.; Buffoli, M.; Capasso, L.; Casuccio, A.; Oliveri Conti, G.; D'Amico, A.; et al. Healthy design and urban planning strategies, actions, and policy to achieve salutogenic cities. Int. J. Environ. Res. Public Health 2018, 15, 2698. [CrossRef]

8. EPA. Healthy Buildings, Healthy People; United States Environmental Protection Agency: Washington, DC, USA, 2001.

9. Annesi-Maesano, I.; Baiz, N.; Banerjee, S.; Rudnai, P.; Rive, S. On behalf of the SINPHONIE Group. Indoor air quality and sources in schools and related health effects. J. Toxicol. Environ. Health Part B 2013, 16, 491-550. [CrossRef]

10. Codinhoto, R.; Tzortzopoulos, P.; Kagioglou, M.; Aouad, G.; Cooper, R. The impacts of the built environment on health outcomes. Facilities 2009, 27, 138-151. [CrossRef]

11. D'Alessandro, D.; Capolongo, S. Ambiente Costruito e Salute: Linee d'Indirizzo di Igiene e Sicurezza in Ambito Residenziale; Franco Angeli: Milano, Italy, 2015; ISBN 9788891725783.

12. Allen, J.; Bernstein, A.; Cao, X.; Eitland, E.S.; Flanigan, S.; Gokhale, M.; Goodman, J.M.; Klager, S.; Klingensmith, L.; Laurent, J.G.C.; et al. Building Evidence for Health. The 9 Foundations of a Healthy Building; Harvard T.H. Chan School of Public Health: Boston, MA, USA, 2017.

13. Al horr, Y.; Arif, M.; Katafygiotou, M.; Mazroei, A.; Kaushik, A.; Elsarrag, E. Impact of indoor environmental quality on occupant well-being and comfort: A review of the literature. Int. J. Sustain. Built Environ. 2016, 5, 1-11. [CrossRef]

14. Pini, A.; Grandoni, L.; Leuzzi, G.; Monti, P.; Di Bernardino, A.; Pelliccioni, A.; Gherardi, M.; Cattani, G.; Di Menno Di Bucchianico, A. A simplified analytical model of ultrafine particle concentration within an indoor environment. IOP Conf. Ser. Earth Environ. Sci. 2020, 489. [CrossRef] 
15. De Martino, A. Linee-guida per la tutela e la promozione della salute negli ambienti confinati. Ig. Sanita Pubbl. 2014.

16. EPA; OAR. Introduction to Indoor Air Quality. United States Environmental Protection Agency: Washington, DC, USA, 2016.

17. Settimo, G.; D'Alessandro, D. European community guidelines and standards in indoor air quality: What proposals for Italy. Epidemiol. Prev. 2014, 38, 36-41.

18. Mazuch, R. Salutogenic and biophilic design as therapeutic approaches to sustainable architecture. Archit. Des. 2017, 87, 42-47. [CrossRef]

19. Breslow, L. Health measurement in the third era of health. Am. J. Public Health 2006, 96, 17-19. [CrossRef] [PubMed]

20. Roskams, M.; Haynes, B. Salutogenic workplace design: A conceptual framework for supporting sense of coherence through environmental resources. J. Corp. Real Estate 2019, 22, 139-153. [CrossRef]

21. International Well Building Institute. 2018 Report The International Well Building Institute Major Takeaways From 2018; The International WELL Building Institute: New York, NY, USA, 2018.

22. Davis, G.; Szigeti, F. Are Facilities Measuring up? Matching Building Capabilities to Functional Needs using the Serviceability Tools and Methods. In Durability of Building Materials and Components 8; Institute for Research in Construction: Ottawa, ON, Canada, 1999; pp. 1856-1866.

23. Davis, G.; Ventre, F.T. Performance of Buildings and Serviceability of Facilities; American Society for Testing and Materials: West Conshohocken, PA, USA, 1990; ISBN 0803112920.

24. Becker, R. Fundamentals of performance-based building design. Build. Simul. 2008, 1, 356-371. [CrossRef]

25. Foliente, G.C. Performance Based Building RED Roadmap; Performance Based Building Network (PeBBu): Rotterdam, The Netherlands, 2005; ISBN 90-6363-048-4.

26. Geyer, P. Component-oriented decomposition for multidisciplinary design optimization in building design. Adv. Eng. Informatics 2009, 23, 12-31. [CrossRef]

27. WHO Regional Office for Europe. WHO Guidelines for Indoor Air Quality: Selected Pollutants; WHO: Copenhagen, Denmark, 2010; Volume 35.

28. Cony Renaud Salis, L.; Abadie, M.; Wargocki, P.; Rode, C. Towards the definition of indicators for assessment of indoor air quality and energy performance in low-energy residential buildings. Energy Build. 2017, 152, 492-502. [CrossRef]

29. Sanguinetti, P.; Abdelmohsen, S.; Lee, J.; Lee, J.; Sheward, H.; Eastman, C. General system architecture for BIM: An integrated approach for design and analysis. Adv. Eng. Inform. 2012, 26, 317-333. [CrossRef]

30. Lu, Y.; Wu, Z.; Chang, R.; Li, Y. Building Information Modeling (BIM) for green buildings: A critical review and future directions. Autom. Constr. 2017, 83, 134-148. [CrossRef]

31. Kirkegaard, P.H.; Kamari, A. Building Information Modeling (BIM) for Indoor Environmental Performance Analysis; Aarhus University: Aarhus, Denmark, 2017.

32. Jung, N.; Häkkinen, T.; Rekola, M. Extending capabilities of bim to support performance based design. J. Inf. Technol. Constr. 2018, 23, 16-52.

33. Hjelseth, E. BIM-based Model Checking (BMC). In Building Information Modeling; Issa, R.R.A., Olbina, S., Eds.; American Society of Civil Engineers: Reston, VA, USA, 2015; pp. 33-61. ISBN 9780784479131. [CrossRef]

34. Hjelseth, E. Converting performance based regulations into computable rules in BIM based model checking software. In eWork and eBusiness in Architecture, Engineering and Construction: Proceedings of the European Conference on Product and Process Modelling (ECPPM 2012); CRC Press: Boca Raton, FL, USA, 2012; pp. 461-469. [CrossRef]

35. Lee, S.; Tae, S.; Roh, S.; Kim, T. Green template for life cycle assessment of buildings based on building information modeling: Focus on embodied environmental impact. Sustainability 2015, 7, 16498-16512. [CrossRef]

36. Cofaigh, E.O.; Fitzgerald, E.; Alcock, R.; McNicholl, A.; Peltonen, V.; Marucco, A. A Green Vitruvius: Principles and Practice of Sustainable Architectural Design; James \& James: London, UK, 1999.

37. Wang, W.; Zmeureanu, R.; Rivard, H. Applying multi-objective genetic algorithms in green building design optimization. Build. Environ. 2005, 40, 1512-1525. [CrossRef]

38. Getuli, V.; Ventura, S.M.; Capone, P.; Ciribini, A.L.C. BIM-based code checking for construction health and safety. Procedia Eng. 2017, 196, 454-461. [CrossRef]

39. Bergonzoni, G.; Capelli, M.; Drudi, G.; Viani, S.; Conserva, F. Building information modeling (BIM) for LEED $^{\circledR}$ IEQ category prerequisites and credits calculations. In eWork and eBusiness in Architecture, Engineering and Construction: Proceedings of the 11th European Conference on Product and Process Modelling (ECPPM 2016), Limassol, Cyprus, 7-9 September 2016; CRC Press: Boca Raton, FL, USA, 2016; pp. 75-79. 
40. Politi, S.; Bergonzoni, G.; Cincotta, I.W.J.; Sampietro, F. LCA analysis through a Visual Programming tool: Workflow on a BIM model case study. in_Bo 2018, 9, 104-115.

41. buildingSMART IFC Standard. Available online: https://standards.buildingsmart.org/IFC/RELEASE/IFC4_1 /FINAL/HTML/ (accessed on 1 May 2020).

42. Diroots Manage Revit Paramaters in Project and Family Environments. Available online: https://diroots.co m/plugins/paramanager-manage-revit-parameters/ (accessed on 1 May 2020).

43. Autodesk Autodesk Model Checker for Revit. Available online: https://biminteroperabilitytools.com/model checker.php (accessed on 10 May 2020).

44. The Ohio State University Building Information Modeling | Planning, Architecture and Real Estate. Available online: https://pare.osu.edu/services/facilities-information-and-technology-services/buildinginformation-modeling (accessed on 10 May 2020).

45. Huang, H.; Haghighat, F. Modelling of volatile organic compounds emission from dry building materials. Build. Environ. 2002, 37, 1349-1360. [CrossRef]

46. Liang, W.; Gao, P.; Guan, J.; Yang, X. Modeling volatile organic compound (VOC) concentrations due to material emissions in a real residential unit. Part I: Methodology and a preliminary case study. Build. Simul. 2012, 5, 351-357. [CrossRef]

47. Persily, A.; Howard-Reed, C.; Nabinger, S.J. Transient analysis of volatile organic compound concentrations for estimating emission rates. Atmos. Environ. 2003, 37, 5505-5516. [CrossRef]

48. The Building Information Foundation. RTS M1 Emission Classification of Building Materials: Protocol for Chemical and Sensory Testing of Building Materials; The Building Information Foundation RTS: Helsinki, Finland, 2017.

49. Wilke, O.; Jann, O. Comparison of formaldehyde concentrations in emission test chambers using EN 717-1 and EN 16516. In Proceedings of the Indoor Air Conference 2018, the 15th Conference of the International Society of Indoor Air Quality \& Climate (ISIAQ), Herndon, VA, USA, 22-27 July 2018.

50. Schieweck, A.; Bock, M.C. Emissions from low-VOC and zero-VOC paints-Valuable alternatives to conventional formulations also for use in sensitive environments? Build. Environ. 2015, 85, 243-252. [CrossRef]

51. Building Research Establishment Environmental Assessment Method BREEAM Certification—Hea 02 Indoor Air Quality. Available online: https://www.breeam.com/BREEAMIntNDR2016SchemeDocument/content/05 _health/hea_02.htm\#Exemplary_level_emission_criteria_byproduct_type (accessed on 10 November 2020).

52. Autodesk Useful IFC links, Revit Products, Autodesk Knowledge Network. Available online: https://knowledge.autodesk.com/support/revit-products/learn-explore/caas/simplecontent/content/usefuluseful-ifc-links.html (accessed on 10 May 2020).

53. Azhar, S.; Carlton, W.A.; Olsen, D.; Ahmad, I. Building information modeling for sustainable design and LEED ${ }^{\circledR}$ rating analysis. Autom. Constr. 2011, 20, 217-224. [CrossRef]

54. Chen, P.-H.; Nguyen, T.C. Integrating web map service and building information modeling for location and transportation analysis in green building certification process. Autom. Constr. 2017. [CrossRef]

55. Maltese, S.; Tagliabue, L.C.; Re Cecconi, F.; Pasini, D.; Manfren, M.; Ciribini, A.L. Sustainability Assessment through Green BIM for Environmental, Social and Economic Efficiency. Procedia Eng. 2017, 180, 520-530. [CrossRef]

56. ACCA Software IFC Viewer-usBIM.viewer+-ACCA Software. Available online: https://www.acca.it/ifc-bi m-viewer (accessed on 1 June 2020).

57. Haghighat, F.; Huang, H. Integrated IAQ model for prediction of VOC emissions from building material. Build. Environ. 2003, 38, 1007-1017. [CrossRef]

58. Liu, Z.; Ye, W.; Little, J.C. Predicting emissions of volatile and semivolatile organic compounds from building materials: A review. Build. Environ. 2013, 64,7-25. [CrossRef]

Publisher's Note: MDPI stays neutral with regard to jurisdictional claims in published maps and institutional affiliations. 